\title{
The Impact of Purinergic System Enzymes on Noncommunicable, Neurological, and Degenerative Diseases
}

\author{
Margarete Dulce Bagatini ${ }^{1},{ }^{1,2}$ Alessandra Antunes dos Santos, ${ }^{3}$ \\ Andréia Machado Cardoso, ${ }^{1,2}$ Aline Mânica, ${ }^{2}$ Cristina Ruedell Reschke, ${ }^{4}$ \\ and Fabiano Barbosa Carvalho ${ }^{2,5}$ \\ ${ }^{1}$ Coordenação Acadêmica, Universidade Federal da Fronteira Sul, Campus Chapecó, Chapecó, SC, Brazil \\ ${ }^{2}$ Programa de Pós-graduação em Ciências Biológicas-Bioquímica Toxicológica, Universidade Federal de Santa Maria, Santa Maria, \\ RS, Brazil \\ ${ }^{3}$ Department of Molecular Pharmacology, Albert Einstein College of Medicine, Bronx, NY, USA \\ ${ }^{4}$ Department of Physiology and Medical Physics, Royal College of Surgeons in Ireland, Dublin 2, Ireland \\ ${ }^{5}$ Laboratório de Pesquisa em Patologia, Universidade Federal de Ciências da Saúde de Porto Alegre, Porto Alegre, RS, Brazil
}

Correspondence should be addressed to Margarete Dulce Bagatini; margaretebagatini@yahoo.com.br

Received 26 January 2018; Revised 3 July 2018; Accepted 22 July 2018; Published 12 August 2018

Academic Editor: Theresa Hautz

Copyright $\odot 2018$ Margarete Dulce Bagatini et al. This is an open access article distributed under the Creative Commons Attribution License, which permits unrestricted use, distribution, and reproduction in any medium, provided the original work is properly cited.

Evidences show that purinergic signaling is involved in processes associated with health and disease, including noncommunicable, neurological, and degenerative diseases. These diseases strike from children to elderly and are generally characterized by progressive deterioration of cells, eventually leading to tissue or organ degeneration. These pathological conditions can be associated with disturbance in the signaling mediated by nucleotides and nucleosides of adenine, in expression or activity of extracellular ectonucleotidases and in activation of $\mathrm{P} 2 \mathrm{X}$ and $\mathrm{P} 2 \mathrm{Y}$ receptors. Among the best known of these diseases are atherosclerosis, hypertension, cancer, epilepsy, Alzheimer's disease (AD), Parkinson's disease (PD), and multiple sclerosis (MS). The currently available treatments present limited effectiveness and are mostly palliative. This review aims to present the role of purinergic signaling highlighting the ectonucleotidases E-NTPDase, E-NPP, E-5'-nucleotidase, and adenosine deaminase in noncommunicable, neurological, and degenerative diseases associated with the cardiovascular and central nervous systems and cancer. In conclusion, changes in the activity of ectonucleotidases were verified in all reviewed diseases. Although the role of ectonucleotidases still remains to be further investigated, evidences reviewed here can contribute to a better understanding of the molecular mechanisms of highly complex diseases, which majorly impact on patients' quality of life.

\section{Introduction}

Noncommunicable, neurological, and degenerative diseases are characterized by cell loss, ultimately leading to deterioration in quality or function of tissues or organs and possible failure of vital organs [1]. Although the etiology and pathogenesis of these diseases remain unclear, recent advances indicate that the processes of organ deterioration share common core features, including cell injury and dysfunction that contribute to functional and morphological impairment of cells. Despite considerable progress in understanding the molecular mechanisms of these diseases, current therapeutic options are limited, and no effective pharmacological treatment has emerged to date. Elucidation of common and unique mechanisms responsible for the deterioration present in these pathologies may facilitate the identification and development of effective targets and therapies [2]. Furthermore, the search for specific (bio) markers for each human condition-physiological and pathological-is becoming critical.

Elements of the purinergic signaling system are involved in many processes in health and disease conditions [3]. 
Therefore, a complete understanding of purinergic system could potentially unveil possible markers or relevant pathways for pathological processes, mainly related to human degeneration. Briefly, the purinergic system consists of three main components: (i) the extracellular nucleotides and nucleosides, which mediate signaling; (ii) the receptors through which these nucleotides and nucleosides exert their effects; (iii) and the ectoenzymes, responsible for the control of extracellular levels of these molecules [4]. The control of the levels of extracellular nucleotides adenine and adenosine and the consequent signaling by purinergic receptors induced by them is critical in maintaining the physiological processes [5]. This control is performed by ectonucleotidases, which are enzymes anchored to the cell surface or located in the interstitial medium (soluble form) [6].

\section{Purinergic System}

Purines' extracellular role was first demonstrated in 1929 by Drury and Szent-Györgyi [7], which described its actions in mammary hearts [8-10]. Although, only in 1970, Burnstock proposed the term "purinergic" and presented his hypothesis about ATP as an independent neurotransmitter released from nonadrenergic noncholinergic neurons in the intestines, bladder, and gut $[11,12]$. Two years later, Burnstock described adenosine triphosphate (ATP) as an extracellular signaling molecule and its effects [13]. However, the purinergic system and ATP had an arduous path to be accepted by the scientific community. Only in 2006, ATP was finally recognized as a cotransmitter in both the peripheral and central nervous systems (CNS) [9, 10, 14], and the purinergic signaling was recognized as a system involved in many nonneuronal and neuronal mechanisms [12].

ATP is the most versatile nucleotide and the primary energy source for cellular functions. Hundreds of reactions in the cell, from metabolic transformations to signaling events, are coupled to the hydrolysis of ATP [15]. Intracellularly, ATP is stored at very high levels (from 5 to $10 \mathrm{mmol} / \mathrm{l}$ ), which can quickly be degraded by ubiquitous extracellular nucleotidases after connecting to specific receptors under physiological conditions. In fact, extracellular ATP has an extremely short half-life before it is degraded to adenosine-milliseconds to seconds. This rapid breakdown results in the activation of a multiplicity of receptor subtypes, which can mediate physiological processes such as proliferation, differentiation, migration, and cell death [16]. On the other hand, the excess of ATP in the brain extracellular space can induce neurotoxicity [17].

ATP stores energy by losing a phosphate group and forming $\mathrm{ADP}$. It has been shown that the ADP molecule can have an important role in platelet aggregation (platelet granules contain high concentrations of ADP), blood vessel tone, cardioprotection, and vascular wall integrity [18].

The critical functions of ATP and its subsequent hydrolysis are initiated upon binding to purinergic receptors, such as P2 nucleotide and P1 adenosine receptors [19]. Abbracchio and Burnstock divided P2 receptors into two families: P2X family of ligand-gated ion channel receptors and the P2Y family of $G$ protein-coupled receptors, based on their molecular structure, induced mechanism of action, and the sequence analysis of cloned $\mathrm{P} 2$ receptors [20].

Currently, thirteen human $\mathrm{P} 2 \mathrm{X}$ receptor subtypes can be distinguished: 6 homomeric (P2X1, P2X2, P2X3, P2X4, $\mathrm{P} 2 \mathrm{X} 5$, and $\mathrm{P} 2 \mathrm{X} 7)$ and 7 heteromeric (P2X1/2, $\mathrm{P} 2 \mathrm{X} 1 / 4$, $\mathrm{P} 2 \mathrm{X} 1 / 5, \mathrm{P} 2 \mathrm{X} 2 / 3, \mathrm{P} 2 \mathrm{X} 2 / 6, \mathrm{P} 2 \mathrm{X} 4 / 6$ [21], and P2X4/7) [22]. $\mathrm{P} 2 \mathrm{X}$ receptors are nonselective ligand-gated ion channels that mediate sodium influx, potassium efflux, and at some extent calcium influx, leading to cell membrane depolarization [23]. The $\mathrm{P} 2 \mathrm{X} 2 / 3$ receptors are located in the nodose ganglia [24], P2X4/6/7 in the CNS $[25,26], \mathrm{P} 2 \mathrm{X} 1 / 5$ in the blood vessels, and $\mathrm{P} 2 \mathrm{X} 2 / 6$ receptors are mainly located in the brain stem $[24,27,28]$. P2X receptors have important functions in the central and peripheral nervous systems, such as slow neuromodulatory function, rapid synaptic transmission, neurotransmitter release, and the generation of pain signals. Furthermore, these receptors have pathophysiological role in injury, inflammation, anxiety, dementia, epilepsy [26], and neurodegenerative disorders such as Alzheimer's and Huntington's diseases [29-32].

P2Y receptors are $G$ protein-coupled receptors, virtually present in all cells, and mainly activated by adenine and uridine nucleotides. There are eight subtypes of $\mathrm{P} 2 \mathrm{Y}$ receptors (P2Y1, P2Y2, P2Y4, P2Y6, P2Y11, P2Y12, P2Y13, and P2Y14), which are ubiquitously expressed in body, including the CNS [32]. They activate intracellular signaling cascades to regulate a variety of cellular and peripheral pathophysiological processes, including inflammation, ischemia, and pain $[32,33]$. In the brain, P2Y receptors exert important roles in neurotransmission, glia cell communication, and neurogenesis due to their localization on neurons, oligodendrocytes, microglia, and astrocytes [13, 34-36].

After release and binding to specific receptors, ATP and other nucleotides undergo rapid enzymatic degradation by ectonucleotidases [4]. Ectonucleotidase families include the ectonucleoside triphosphate diphosphohydrolases (ENTPDase/CD39/NTPDase 1), ectonucleotide pyrophosphatase/phosphodiesterases (E-NPP), and ecto- $5^{\prime}$-nucleotidase (E-5' -nucleotidase/CD73). E-NTPDases and E-NPPs hydrolyze ATP and ADP to adenosine monophosphate that is further hydrolyzed by E- $5^{\prime}$-nucleotidase to adenosine $[6,37,38]$.

Since 1929, adenosine has been recognized as a biologically significant molecule, responsible for regulating multiple systems including cardiac conduction, arterial pressure, and intestinal motility [7]. Adenosine is produced both intracellularly and extracellularly through enzymatic degradation of adenine nucleotides $[39,40]$. The maintenance of its levels in the extracellular fluids is the result of the balance between its production and consumption [19]. Indeed, adenosine synthesis is controlled by ectonucleotidases located on the cytoplasmatic membrane, and its concentrations vary according to physiological and pathological stimuli such as hypoxia and inflammation $[41,42]$. Extracellular adenosine is involved in many cytoprotective functions of the body, including conditioning the heart against ischemia, counteracting the damaging effects of excitotoxicity and seizure activity in the brain, and suppressing excessive immune and inflammatory responses. Finally, extracellular adenosine 


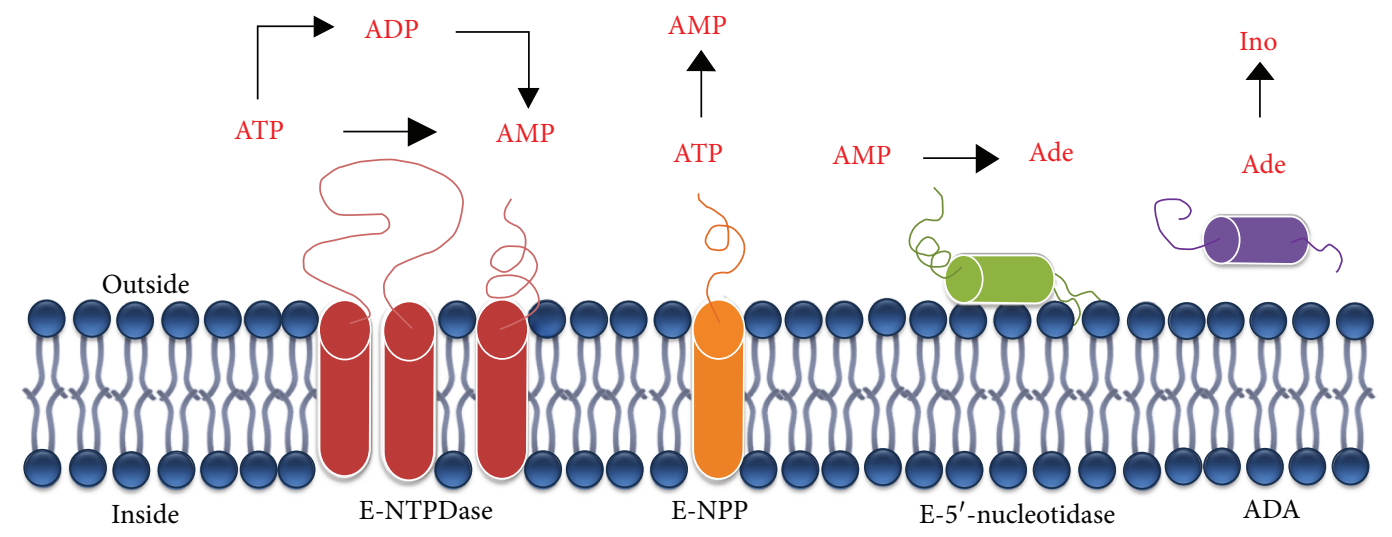

FIgURE 1: Cell membrane-anchored ectonucleotidases and their respective hydrolysis reactions.

can be deaminated to inosine by adenosine deaminase (ADA) [43].

Critically, the understanding of the physiological and pharmacological roles of adenosine was greatly facilitated by localizing the different $\mathrm{P} 1$ receptor subtypes in target tissues and identifying its four subtypes-A1, A2A, A2B, and $A 3$ receptors [44-46]. These are $G$ protein-coupled receptors, which present inhibitory action upon adenosine binding [20]. P1 receptors are widely located in the brain and in peripheral tissues, such as the heart, kidney, and adrenals of different species $[45,46]$.

After the binding to receptors, the nucleotides and nucleosides are rapidly degraded by specific hydrolase enzymes, which occurs via different ways [47]. The E-NTPDase catalyzes ATP and ADP hydrolyses, which culminates into AMP formation. E-5' -nucleotidase is responsible for AMP degradation leading to adenosine formation. Alkaline phosphatase removes inorganic phosphate $(\mathrm{Pi})$ of a broad range of substrates, including nucleotides (ATP, ADP, and AMP) producing adenosine (Figure 1) [48, 49]. The producing adenosine is converted into inosine by adenosine deaminase (ADA) [38].

The E-NTPDase family is very efficient in controlling the bioavailability of ATP [49]. This family consists of eight members, E-NTPDases 1-8, which differ in substrate specificity, tissue distribution, and cellular localization [50]. Members 1, 2, 3, and 8 are the principal enzymes responsible for the hydrolysis of tri- and diphosphate nucleotides on the cell surface under physiological conditions. E-NTPDases 4, 5, 6 , and 7 are associated with intracellular organelles [50]. These ectoenzymes are anchored to the plasma membrane via hydrophobic domains with the active site facing the extracellular medium [5, 38, 48].

The E-5'-nucleotidase family is comprised of seven isolated and characterized isoforms with different nomenclature, depending on the subcellular localization. Five isoforms are cytosolic, one is located in the mitochondrial matrix, and one is related to the outer plasma membrane [47]. This enzyme generates extracellular adenosine from AMP, as previously mentioned, and its activity is the rate-limiting step of adenosine formation from adenine nucleotides in most tissues $[49,51]$.
The E-NPPs are transmembrane glycoprotein type II enzymes, which are able to catalyze many different reactions: $3^{\prime}-5^{\prime}$-cyclic adenosine monophosphate $\left(5^{\prime}\right.$-cAMP) to AMP; ATP to AMP and inorganic diphosphate (PPi); AMP to $\mathrm{ADP}$ and inorganic phosphate (Pi); nicotinamide adenine dinucleotide oxidized $\left(\mathrm{NAD}^{+}\right)$to AMP and mononucleotide nicotinamide [6]. Although this family of enzymes is composed by 7 members, only E-NPPs 1, 2, and 3 are able to hydrolyze nucleotides [5].

ADA activity has been found altered in various pathological conditions including acquired immunodeficiency syndrome (AIDS), anemia, lymphomas, tuberculosis, and leukemia [47]. In humans, different $\mathrm{ADA}$ isoforms have been identified: adenosine deaminase-1 (ADA-1), adenosine deaminase-2 (ADA-2), and adenosine deaminase-3 (ADA-3) [52]. ADA-1 plays a metabolic role not only as a key cytosolic enzyme in the purine pathway but also as an ectoenzyme by regulating extracellular adenosine levels. In contrast, ADA-2 is specifically designed to act in the extracellular environment according to its presence in the serum [53]. Thus, ADA can be considered as a multifunctional protein, playing several roles and importantly regulating biological systems, which consequently impacts on human health [53].

\section{Noncommunicable, Neurological, and Degenerative Diseases}

According to the World Health Organization (WHO), chronic disorders account for 38 million deaths each year, more than $80 \%$ of all deaths worldwide. Cardiovascular diseases cause most of the deaths (17.5 million per annum), followed by cancers ( 8.2 million), respiratory diseases (4 million), and diabetes (1.5 million) $[54,55]$. In the last two decades, this profile of morbidity and mortality causes around the world has significantly been changed, and, increasingly, chronic neurological and degenerative diseases are becoming more prominent [54].

Among the better-known chronic diseases are the noncommunicable, such as atherosclerosis, hypertension, diabetes, and cancer; the neurological, such as epilepsy; and the neurodegenerative, such as Alzheimer's disease (AD), 
TABle 1: Ectonucleotidases (E-NTPDase, E-5'-nucleotidase, and ADA) and purinergic receptors in experimental models and patients with atherosclerosis.

\begin{tabular}{|c|c|c|c|c|c|}
\hline Sample & E-NTPDase & $\mathrm{E}-5^{\prime}$-nucleotidase & $\begin{array}{l}\text { Adenosine } \\
\text { deaminase }\end{array}$ & $\begin{array}{l}\text { Involved } \\
\text { receptors }\end{array}$ & Reference \\
\hline $\begin{array}{l}\text { Endothelial cells and thoracic aorta from } \\
\text { mouse model of atherosclerosis }\end{array}$ & $\begin{array}{l}\downarrow \text { enzymatic activity } \\
\text { and expression }\end{array}$ & - & - & - & {$[72,84]$} \\
\hline ApoE-deficient mice & - & $\begin{array}{l}\downarrow \text { enzymatic activity } \\
\text { and expression }\end{array}$ & - & - & {$[88]$} \\
\hline Platelets and plasma from patients & $\downarrow$ enzymatic activity & $\uparrow$ enzymatic activity & - & - & {$[90]$} \\
\hline Plasma of experimental model & - & - & $\uparrow$ enzymatic activity & A1 upregulation & [93] \\
\hline $\begin{array}{l}\text { Atherosclerotic vessel wall from } \\
\text { aortoiliac bifurcation of Apoliprotein E- } \\
\text { and LDL-deficient animals }\end{array}$ & - & - & $\downarrow$ enzymatic activity & - & {$[92]$} \\
\hline
\end{tabular}

Parkinson's disease (PD), and multiple sclerosis (MS). The study and control of these diseases are exceedingly difficult due to their multiplicity and diversity, for instance, the interconnection network of risk and protective factors, diverse onsets followed by multistep pathogenesis, and, in some cases, multifocal localization [56]. A common feature among many of the neurological, neurodegenerative, and several aspects of cardiovascular diseases may be a component of degeneration. It means that at some stage occurs loss of cells, subcellular function, or tissue elements or function [57]. In fact, these diseases may also share other pathological features or events, such as evidence of membrane damage, oxidative stress, mitochondrial dysfunction, and upregulation of autophagy [58].

Once purinergic signaling is involved in virtually all body functions, the roles of purines might be altered in pathological states in different body systems [59]. Indeed, purinergic mechanisms and specific receptor subtypes have been shown to be involved in several pathologies including brain trauma and ischemia, neurodegenerative diseases involving neuroimmune and neuroinflammatory reactions [60], diabetes [61], vascular diseases including atherosclerosis $[62,63]$, and hypertension $[9,10]$. Importantly, studies have shown the potential of purinergic mechanisms as therapeutic targets for the treatment of neurological [36] and degenerative disorders $[9,64,65]$. Moreover, the currently used strategies in searching for novel purinergic targeting drugs include the development of (i) selective agonist and antagonist ligands for the P2X and P2Y receptors, (ii) inhibitors of extracellular catabolism of purines, and (iii) modulators of nucleotide and nucleoside transport [66]. Adenosine signaling manipulation may also have therapeutic potential in neurodegenerative diseases such as $\mathrm{AD}, \mathrm{PD}$, and Huntington's diseases and in neurological and psychiatric disorders such as epilepsy [67], schizophrenia, and autism [68].

Taking that into account, the next section provides an overview of recent findings regarding the role of purinergic system enzymes in the pathophysiology of noncommunicable, neurological, and degenerative diseases. Considerable attention has been directed towards diseases related to the cardiovascular system (atherosclerosis and hypertension), cancer, and central nervous system (epilepsy, Alzheimer's disease, Parkinson's disease, and multiple sclerosis).
3.1. Atherosclerosis. Atherosclerosis is popularly defined as an artery wall thickening triggered by accumulation of foam cells and proliferation of intimal smooth muscle cell, which results in a fibrofatty plaque. Atherosclerotic disease still is the worldwide leading cause of cardiovascular complications and death [69]. The drivers for atherosclerotic plaque development include fluid shear forces, lipid milieu, cells of the vascular wall, and cells recruited from the circulation. However, one of the central events that results in the atherosclerosis development is the disturbance in blood flow in human arteries. In addition, some cells, such as endothelial cells, platelets, monocytes, and T cells, can be involved and/or activated in response to changes in blood flow [70].

Arteries presenting constant flow are further resistant to plaque formation when compared to arteries presenting disturbance in blood flow. Taking this into account, it is important to point out that the aspects that control the blood flow, such as genes, microRNAs, and epigenomic processes, initiate responses that can result in activated or quiescent endothelial phenotypes and, in turn, susceptibility to or protection from atherosclerosis [70-72]. Corroborating with this, Nam and collaborators demonstrated that disturbed flow directly causes atherosclerosis within 14 days, under hyperlipidemic conditions, after partial carotid ligation surgery [71].

It is well stablished that E-NTPDase 1 is the major ectonucleotidase expressed in blood vessels. Several studies have been carried out in order to elucidate the role of this enzyme in controlling the blood flow, atherosclerosis development, and inflammation related to vascular disorders [70, 73] (Table 1). It has been widely shown that E-NTPDase 1 expressed in both endothelial and smooth muscle cells, along with autonomic nervous system, can control the contraction of arteries, which directly influences the regulation of blood circulation [49, 74-77]. Moreover, E-NTPDase 1 plays a critical role limiting the activation of some $\mathrm{P} 2$ receptors, thus, preventing its desensitization in endothelial and smooth muscle cells, consequently, preventing excessive artery contraction [76-79]. This fact can be explained because ATP, released from sympathetic nerves, along with norepinephrine (NE) and neuropeptide $\mathrm{Y}$, can activate $\mathrm{P} 2 \mathrm{X}$ receptors at postjunctional membranes evoking vascular smooth muscle 
contraction, which generally potentiate the effects of NE at $\alpha 1$-adrenoceptors [51, 80]. Accordingly, Cardoso et al. have shown that E-NTPDase 1 expression and activity have the ability to control the effects of sympathetic nervous system in the vasculature [81].

Regarding to the vascular injury related to atherogenesis, it has been shown that E-NTPDase 1 naturally results in protection from the action of nucleotides released from the injured cell in vasculature or activated platelets by eliminating these prothrombotic and proinflammatory stimuli, that is, by metabolizing extracellular ATP and ADP. In a recent work, Kanthi et al. have evaluated the role of E-NTPDase 1 in the development of atherogenesis, in an apolipoprotein E-deletion mouse model of atherosclerosis (ApoE-deficient) [70]. ApoE-deficient group, fed with a high-fat diet, showed evidently augmented and plaque formation along with platelet activation that was verified by some circulating markers. In this work, the authors also showed that in regions of stable flow, E-NTPDase 1 was markedly present in ApoE-deficient mice. In contrast, E-NTPDase 1 was reduced in atheroprone as subject to disturbed flow. Moreover, in this same work, it has been demonstrated that the deregulated flow triggered by a partial carotid artery ligation quickly suppressed endothelial E-NTPDase 1 expression. Furthermore, unidirectional laminar shear stress induced atheroprotective ENTPDase 1 expression in human endothelial cells. In these conditions, the vascular transcription factor involved in the E-NTPDase 1 is the Krüppel-like factor 2 (KLF2), which can bind near the transcriptional start site of E-NTPDase 1.

Mercier and collaborators have shown that ApoE knockout mice displayed decreased E-NTPDase 1 expression and activity in the thoracic aorta, which correlates with reduced vascular reactivity and presence of atherosclerotic plaques in aortic roots and arches. The authors have speculated that the accumulation of ATP and ADP in ApoE knockout mice may cause desensitization of $\mathrm{P} 2$ receptors, which in turn may contribute to decreased blood flow and may predispose an individual to atheroma formation [82]. In a carotid artery wire injury model, E-NTPDase 1 knockout mice showed decreased migration of vascular smooth muscle cells and reduced neointimal formation, indicating that CD39 contributes to a harmful neointima formation [83]. Taken together, these data establish that the key regulator of atherosclesosis development driven by shear stress is the E-NTPDase 1 enzyme. Kanthi et al. have unveiled what is now believed to be a previously unrecognized role for E-NTPDase 1 as an endogenous regulator of endovascular purine levels, serving as a modulator of crucial cellular drivers of atherogenesis [70]. Emphasizing the role of E-NTPDase 1 in providing anti-inflammatory and antithrombotic mediator adenosine, it has been shown that therapeutic strategies targeting CD39 offer promising opportunities in the management of vascular thromboinflammatory diseases [73].

CD73 also has been reported playing a key role in the atherogenic process by driving purinergic signaling [84, 85]. In a work developed by Buchheiser et al., it was demonstrated that the inactivation of CD73 promotes atherogenesis in apolipoprotein E-deficient mice [86]. The ablation of CD73 in ApoE knockout animals triggered an augmentation in atheroma formation, which was probably generated by the reduced inhibitory control exerted by adenosine on immune cells, which are dynamically related to the atherogenic process [86]. The role of CD73 in protection against atherosclerosis was also observed after injury of carotid arteries. This condition results in augmented expression of vascular cell adhesion molecule- (VCAM-) 1 and increased nuclear factor-kappa B activity, which triggers the formation of neointimal plaque and continuous infiltration of macrophage in CD73 knockout animals when compared to control groups [87].

Jalkanen and collaborators have evaluated 226 patients with stable peripheral artery disease admitted for nonurgent invasive imaging and treatment. They verified that the progression of atherosclerosis is associated with low ENTPDase 1 activity and high CD73 [88]. Same authors also found high levels of ATP and ADP in the plasma of those patients, suggesting that low E-NTPDase 1 activity is associated with ATP- and ADP-induced platelet aggregation and trombus formation [88].

Since adenosine is the main molecule that presents antithrombotic effects, $\mathrm{ADA}$ also has a key role in atherogenesis process. This enzyme has been suggested as an inflammatory marker [89], and its high expression and activity were associated with the risk of atherosclerosis development $[89,90]$. Kalvegren et al. have verified changes in metabolism of extracellular nucleotides in the atherosclerotic vessel wall from aortoiliac bifurcation of apoliprotein E- and LDLdeficient animals (ApoE/LDLr (-/-)). They observed that the ADA activity was decreased as well as the levels of adenosine in ApoE/LDLr (-/-) mice when compared to littermate control, reinforcing the idea that low ADA activity is a predictor of atherogenesis. Another mechanism that can contribute to the development of atherosclerosis is that high levels of ADA can increase the release of reactive oxygen species from neutrophils, through a downregulation of the inhibitory adenosine/cAMP system and an enhanced activation of A1 receptors. This sustained neutrophil activation could also contribute to inflammatory disorders and atherogenesis [91].

Genetic studies have been performed regarding the relationship between ADA and atherosclerosis, and two main points can be highlighted: (1) single-nucleotide polymorphisms of the RNA-specific gene of ADA are associated with metabolic disorders in general and atherosclerosis [92] and (2) high ADA gene expression is related to the augmentation of cathepsin S mRNA, which encodes a cysteine protease associated with angiogenesis and atherosclerosis [93].

Taking the above information into account, it is possible to conclude that a high expression and activity of E-NTPDase 1 and CD73, in order to generate adenosine, and a low expression and activity of ADA, in order to keep the levels and let the adenosine molecule exerts its antithrombotic effects, may exert a positive effect in preventing atherosclerosis.

3.2. Hypertension. Hypertension is a highly prevalent disease, which is estimated to affect $26 \%$ of the worldwide adult population $[94,95]$. Hypertension is defined by a systolic 
blood pressure (BP) of $140 \mathrm{mmHg}$ or higher, a diastolic $\mathrm{BP}$ of $90 \mathrm{mmHg}$ or higher, or currently using BP-lowering drugs [95]. The disease represents a major risk factor for the development of kidney failure, coronary events, cerebrumvascular disease, heart failure, and peripheral vascular disease $[94,95]$. Hypertension is the leading cause of morbidity and mortality worldwide while cigarette-smoking is the major preventable cause of death [96]. Nowadays, most patients require more than one drug to achieve $\mathrm{BP}$ target, and monotherapy would only be sufficient in about $20-30 \%$ of patients [95]. This fact highlights the unmet need to unveil other mechanisms that can be associated with hypertension development and maintenance.

Among the events related to hypertension, we can cite platelet activation and aggregation, vasoconstriction, and low-grade inflammatory status. It is well known that the purinergic system enzymes are tightly involved regulating nucleotides that can trigger or protect against platelet aggregation. Moreover, the control of extracellular circulating nucleotides by ectonucleotidases is related to both anti- and proinflammatory status [49]. Recently, Fabbiano and collaborators have demonstrated that regulatory $\mathrm{T}$ (TReg) cell-expressing E-NTPDase 1 require an immunosuppression-independent mechanism to counteract renal and possibly cardiac damage during angiotensin II- (AngII-) dependent hypertension [97]. Tissue-resident neutrophils suffer apoptosis by ATP hydrolysis of E-NTPDase 1. The same group also stated that genetic alterations in the number of TReg and TH cells has an influence on tissue-resident neutrophil number, cardiomyocyte hypertrophy, cardiorenal fibrosis, and elevation of arterial pressure during AngII-induced hypertension [97]. Thus, TReg cell-expressing E-NTPDase 1 can protect against hypertension-driven fibrosis in tissue.

In pulmonary arterial hypertension (PAH), two independent studies have been performed with different outcomes. Using human samples, in vitro strategies, and a rat model, Helenius et al. have demonstrated that the suppression of E-NTPDase 1 is linked to the pathogenesis of PAH [98]. Furthermore, they stated that the accumulation of extracellular ATP and ADP is strictly linked to vascular dysfunction and remodeling in $\mathrm{PAH}$ and can modulate the disease course in multiple levels. On the other hand, Visovatti et al. have observed that microparticles from platelets and endothelial cells of patients with PAH display increased E-NTPDase 1 activity and expression [99]. Therefore, more studies are crucial to elucidate whether high or low levels of ENTPDase 1 can be related to PAH development.

Taking advantage of a preeclampsia mouse model, McRae et al. have evaluated the impact of E-NTPDase 1 overexpression. In this study, the authors injected Th1-polarized cells on pregnancy days 10 and 12 of wild-type and ENTPDase 1 transgenic mice and measured the systolic blood pressure (SBP) until pregnancy day 15 , when mice were sacrificed. Following transfer of Th1-polarized cells, SBP of E-NTPDase 1 transgenic mice remained unchanged, without evidence of renal lesions, while an increase was observed in pregnant wild-type mice. Thus, the authors have concluded that E-NTPDase 1 overexpression can be protective in a mouse model of preeclampsia [100].
Sympathetic system has a crucial link with hypertension development by controlling vascular tonus. E-NTPDase 2 is associated with the adventitia of muscularized vessels, microvascular pericytes, and other cell populations in the subendocardial space in the heart [75]. Later, Rücker et al. have shown that E-NTPDase 2 is the most expressed ectonucleotidase in synaptosomes prepared from rat heart left ventricles, indicating that this enzyme may be essential for modulating ATP and NE responses on heart fibers [101]. At the same time, the presence of E-NTPDase 2 in the vascular murine adventitial cells [75] also suggests that this enzyme plays a role in hydrolyzing the ATP released from sympathetic nerves and, thus, can help to control vascular tone and hypertension development.

E-5'-nucleotidase is also highly expressed in the left ventricle, and its activity seems to be important for the control of the nucleotide/nucleoside ratio in the vicinity of nerve endings in the heart [101]. Moreover, in human coronary arteries, sympathetic nerves are one of the sources of adenine nucleotides and coronary vasodilation was found to be associated with the endothelial expression of E-5' ${ }^{\prime}$-nucleotidase. Inhibition of $\mathrm{E}-5^{\prime}$-nucleotidase and the usage of P1 antagonists have been associated with a marked reduction of the relaxation of coronary arteries [102]. The same occurs in mesenteric arteries [103] and other vascular beds [51]. Data from Sousa and colleagues have revealed that the increase in the sympathetic tonus in spontaneously hypertensive rats can be associated to a higher NE/ATP release ratio from sympathetic nerves and to deficits in the endogenous inhibitory tonus mediated by prejunctional adenosine A1 receptors [103]. This fact reinforces the important role of E-NTPDase 1, E-NTPDase 2, and CD73 in producing adenosine and preventing hypertension development caused by augmented sympathetic tonus. Indeed, adenosine produced by $\mathrm{E}-5^{\prime}$-nucleotidase activates P1 receptors, which can cause hyperpolarization and relaxation of the underlying vascular smooth muscle cells [102].

Increased E-NTPDase and CD73 activities have been observed in both animal models of hypertension, in human studies, and in platelets and lymphocytes [81, 104-107]. These specific platelet and lymphocyte responses can be understood as a mechanism to ameliorate hypertension through the elevation of adenosine levels, by combined actions of E-NTPDase and CD73.

Taken together, these results indicate that E-NTPDase 1 and CD73 expressed in lymphocytes, TReg cells, endothelial cells, and platelets constitute a protective barrier against hypertension-driven tissue fibrosis. In addition, the results suggest new therapeutic avenues to prevent hypertension and hypertension-linked pathologies.

Changes in ADA expression and activity are also related to hypertension development and maintenance. Human studies have shown increase in ADA activity and expression in response to hypertension and hypertension-associated pathologies, such as metabolic syndrome [108]. A genetic study with hypertensive patients showed that a common polymorphism (C34T) of the ADA gene (isoform 1) is strongly correlated with essential hypertension [109]. ADA 
TABle 2: Ectonucleotidases (E-NTPDase, E-5'-nucleotidase, and ADA) and purinergic receptors in experimental models and patients with hypertension.

\begin{tabular}{|c|c|c|c|c|c|}
\hline Sample & E-NTPDase & $\begin{array}{c}\text { E-5'- } \\
\text { nucleotidase }\end{array}$ & $\begin{array}{l}\text { Adenosine } \\
\text { deaminase }\end{array}$ & Involved receptors & Reference \\
\hline $\begin{array}{l}\text { Treg cells from angiotensin } \\
\text { II-dependent hypertension }\end{array}$ & $\begin{array}{c}\uparrow \text { expression CD39 } \\
\uparrow \text { enzymatic activity } \\
\text { to ATP and ADP }\end{array}$ & - & - & - & [99] \\
\hline Pulmonary arterial hypertension & $\begin{array}{c}\uparrow \text { expression CD39 } \\
\uparrow \text { enzymatic activity } \\
\text { to ATP and ADP }\end{array}$ & - & - & - & {$[100,101]$} \\
\hline Preeclampsia & $\begin{array}{c}\uparrow \text { expression CD39 } \\
\text { can protect against } \\
\text { preeclampsia }\end{array}$ & - & - & - & {$[102]$} \\
\hline Synaptosomes from rat heart & $\begin{array}{l}\uparrow \text { expression of } \\
\text { NTPDase } 2\end{array}$ & $\uparrow$ expression & & & {$[77,103]$} \\
\hline Human coronary arteries & - & $\uparrow$ expression & - & P1 upregulation & {$[104]$} \\
\hline $\begin{array}{l}\text { Platelets and lymphocytes of } \\
\text { hypertensive human }\end{array}$ & $\begin{array}{c}\uparrow \text { expression } \\
\uparrow \text { enzymatic activity }\end{array}$ & $\uparrow$ enzymatic activity & $\uparrow$ enzymatic activity & - & [109-111] \\
\hline $\begin{array}{l}\text { Animal membrane fractions of } \\
\text { renal tissue }\end{array}$ & - & - & $\begin{array}{l}\downarrow \text { enzymatic activity } \\
\text { and expression }\end{array}$ & $\begin{array}{l}\text { A2A downregulation } \\
\text { A3 upregulation }\end{array}$ & {$[113]$} \\
\hline $\begin{array}{l}\text { Platelet of pregnant hypertensive } \\
\text { woman }\end{array}$ & - & - & $\uparrow$ enzymatic activity & - & {$[114,115]$} \\
\hline $\begin{array}{l}\text { Placenta of pregnant hypertensive } \\
\text { woman }\end{array}$ & - & $\begin{array}{c}\uparrow \text { expression } \\
\uparrow \text { enzymatic activity }\end{array}$ & - & - & {$[116]$} \\
\hline
\end{tabular}

activity is also increased in both platelets and lymphocytes in an animal model of hypertension induced by L-NAME administration [81, 104-106].

Moreover, Tofovic et al. have suggested that the inhibition of ADA may provide beneficial effects in old hypertensive animals, and an inhibitor of this enzyme could be designed and used to offer cardiovascular protection in hypertension [110]. Franco and colleagues have analyzed the activity of nucleotidases and ADA in cytosolic and membrane fractions of renal tissue, in an angiotensin-II model of hypertension [111]. They observed a decrease in the membrane ADA activity and expression, in AngII-treated rats. Furthermore, despite the adenosine elevation, A1 and A2B receptor protein expression did not change; in contrast, a downregulation was observed in $\mathrm{A} 2 \mathrm{~A}$ receptors and an upregulation in $\mathrm{A} 3$ receptor levels. A similar pattern was found in the cortex and in the medulla-the expression of A3 receptor decreased in both segments. These results suggest that the elevation of renal tissue and interstitial adenosine contributes to the renal vasoconstriction observed in the AngII-induced hypertension. This can be either mediated by a decrease in the activity and expression of ADA, increased production of adenosine, or an imbalance in adenosine receptors [111].

Original studies have shown increased platelet aggregation as a result of high ADA activity and expression and lack of adenosine in pregnancy hypertensive [112, 113]. It was indeed suggested that ADA activity as well as platelet aggregation could serve as peripheral markers for the development of therapy for the maintenance of homeostasis and inflammatory processes in hypertension and hypertension- associated pathologies $[108,113]$. In contrast, Iriyama et al. have analyzed adenosine metabolism using two different animal models of preeclampsia [114]. They have demonstrated that adenosine levels were high in preeclampsia, and this increase was enough to induce hallmark features of preeclampsia including hypertension, proteinuria, small fetuses, and impaired placental vasculature. This study has also revealed that besides the high levels of adenosine, the receptor A2B was excessively activated, contributing to the development of preeclampsia-related features, although the key finding of this study was that the placental adenosine increase is triggered by the elevation of placental CD73, thereby contributing to preeclampsia [114]. Discrepancies between those two studies can be explained by experimental design differences, for instance, site of analysis (platelets versus placenta). Finally, Iriyama et al. did not evaluate the ADA enzyme. Therefore, more studies are necessary to elucidate whether adenosine causes or protects against preeclampsia and to unveil the actual role of ADA in preeclampsia. This information is summarized in Table 2.

3.3. Cancer. Cancers are considered heterogeneous pathologies that vary by tissue of origin and genomic, proteomic, and metabolic alterations [115]. The inflammation plays an important role in the steps required for cancer metastasis because a wide variety of cytokines and other proinflammatory markers contributes to both the extrinsic and intrinsic pathways of inflammation associated by cancer [116].

The enzymatic chain responsible for ATP hydrolysis and adenosine production, present in all immune and vascular cells, has an important role in the control or promotion 
of inflammation in tumors [117]. This is because of an exuberant immune/inflammatory response, not adequately balanced by endogenous mechanisms of homeostatic control that can lead to persistent and abnormal forms of collateral tissue damage [118]. Adenosine can accumulate in the tumor environment and stroma and generate an immunosuppressed microenvironment that favors the development and metastasis of neoplasias [119].

Multiple mechanisms are involved in adenosine effects, which include inhibition of T helper 1 cell (TH1 cell) cytokine production, deregulation of mononuclear phagocyte cell differentiation and maturation, suppression of effector $\mathrm{T}$ cells, and generation of an angiogenic and matrix remodelling environment that is suitable for cancer growth $[120,121]$. Most of the signaling actions of extracellular adenosine are mediated by $\mathrm{G}$ protein-coupled cell surface receptors that are divided into four subtypes: A1, A2A, $\mathrm{A} 2 \mathrm{~B}$, and $\mathrm{A} 3$ [122].

The extracellular adenosine acts as a local modulator and exerts effects by protecting cells and tissues from an excessive inflammatory response and as favorable to the onset and cancer growth, by favoring angiogenesis and matrix remodeling $[122,123]$. When adenosine active A2A, A2B, and $\mathrm{A} 3$ receptors, macrophages promotes the release of the anti-inflammatory cytokine like as TNF, IL-6, IL-10, IL-12, nitric oxide (NO) and macrophage inflamatory protein(MIP) $-1 \alpha[52,120]$.

The A2A receptor activity, a T-cell surface immune checkpoint protein, could lead to the discovery that adenosine in the tumor microenvironment interferes with antitumor immunity, suggesting that antagonism of the A2A could be an effective cancer immunotherapeutic [124].

3.4. Epilepsy. Epilepsy is a debilitating neurological disease, characterized by recurring, spontaneous, unprovoked seizures. Temporal lobe epilepsy (TLE) is the most common form of acquired epilepsy, affecting people from all ages [125]. The World Health Organization (WHO) reports that epilepsy affects approximately 50 million people worldwide, with about a third of patients either resistant to current antiepileptic drugs (AED) or experiencing unacceptable side effects.

Neuroinflammation is increasingly recognized as one of the key players in seizure generation and propagation and in the maintenance of the epileptic phenotype [126]. During pathological conditions with increased neuronal firing or cell death nucleotides, ATP is released into the extracellular space in the brain. Although studies show discrepancies about ATP release during seizures and chronic epileptic state, this is possibly due to ATP rapid hydrolysis, by ectonucleotidases in the extracellular space, making it difficult to directly measure its release [127]. Once released, ATP activates P2 receptors (P2X and $\mathrm{P} 2 \mathrm{Y})$, mediating the release of gliotransmitters, which triggers neuronal hyperexcitability and neuroinflammation. Taking advantage of experimental models of epilepsy, the expression and function of $\mathrm{P} 2 \mathrm{X}$ receptors have been well established in research field $[36,128]$. However, only recently has been suggested that the P2Y receptor subfamily plays a relevant role in experimental and human epilepsy [67, 129]. Furthermore, while adenosine anticonvulsant properties are well established [130], the contribution of extracellular nucleotides to seizures and epilepsy pathology is an area to be further explored [36]. Therefore, not only the targeting of molecules involved in inflammatory pathways but also the targeting of purinergic signaling or their combination seems relevant approaches for developing novel therapies for epilepsy [36, 126].

3.5. Alzheimer's Disease. Alzheimer's disease (AD), the leading cause of dementia worldwide, is a progressive neurodegenerative disease associated with the deposition of $\beta$-amyloid peptide $(\mathrm{A} \beta)$ within the brain, along with intracellular neurofibrillary tangles (NFTs) mainly formed by hyperphosphorylated tau protein [131]. The impairment of mitochondrial function and reduction of ATP levels are pathological conditions found in $\mathrm{AD}$, which is closely linked to the decline of cognitive processes $[132,133]$. It is well known that in the brain, ATP is secreted by the neurons, glia, and endothelial cells that constitute the blood-brain barrier. Coincident with its release is the secretion of soluble ectonucleotidases which control the effective ATP concentration by breaking it down to adenosine [134]. The involvement of ectonucleotidases on the process of learning and memory in rats has already been described [135-137]. It has also been shown that P2X7 purinergic receptors are upregulated in the brain of patients with $\mathrm{AD}$ and in animal models $[138,139]$. Interestingly, inhibition of $\mathrm{P} 2 \mathrm{X} 7$ in mice, transgenic for mutant human amyloid precursor protein, reduced the number of amyloid plaques in the hippocampus [140] and stimulation of P2X7 receptors on human macrophages and microglia enhanced the degenerative lesions observed in AD [141] (Tables 3 and 4). Furthermore, direct alterations of purine metabolism have been detected in $\mathrm{AD}$ by metabolomics, in the ventricular cerebrospinal fluid at postmortem [142], cerebrospinal fluid in living individuals [142-144], and AD brains [145].

Ectonucleotidase activities may be involved in the early events related to memory acquisition and consolidation of an aversively motivated learning task $[135,136]$. Previous studies performed in animals subjected to scopolamine model of dementia, which mimics the memory deficit observed in diseases characterized by impairment in cholinergic neurotransmission, such as AD [146-148], have shown a marked reduction in the ATP levels and changes in ectonucleotidase activities (E-NTPDase, E-5' ${ }^{\prime}$-nucleotidase, and $\mathrm{ADA}$ ), in the cerebral cortex and hippocampus of rats $[149,150]$.

Tissue-nonspecific alkaline phosphatase (TNAP) is one of four alkaline phosphatase isozymes that has been described as an ectonucleotidase being able to cleave all forms of adenosine phosphates, influencing purinergic signaling [48]. Preclinical assays tested on more than 100 $\mathrm{AD}$ patients have demonstrated that TNAP activity is significantly increased in the hippocampus of $\mathrm{AD}$ patients compared with age-related controls [151]. In fact, it has been shown that the extracellular hyperphosphorylated tau protein coming from damaged neurons must be dephosphorylated to become an agonist of a muscarinic receptor 
TABLE 3: Role of purinoreceptors in experimental models and patients with Alzheimer's disease (AD) and Parkinson's disease (PD).

\begin{tabular}{|c|c|c|c|}
\hline R Sample & $\mathrm{P} 2 \mathrm{X} 7$ receptor & $\mathrm{A} 2 \mathrm{~A}$ receptor & Reference \\
\hline $\begin{array}{l}\text { Transgenic mouse model of AD } \\
\text { (brain slices) }\end{array}$ & Upregulated & - & [169] \\
\hline $\begin{array}{l}\text { Microglia from AD patients } \\
\text { Human microglia treated with } \\
\text { amyloid-beta peptide in vitro } \\
\text { Rat hippocampus after amyloid-beta } \\
\text { peptide injection }\end{array}$ & Upregulated & - & {$[170]$} \\
\hline Transgenic mouse model of AD & $\begin{array}{l}\text { Inhibition of P2X7R decreased the } \\
\text { number of hippocampal amyloid plaques }\end{array}$ & - & {$[171]$} \\
\hline $\begin{array}{l}\text { Human macrophages and microglia } \\
\text { preactivated with amyloid-beta peptide }\end{array}$ & $\begin{array}{l}\text { P2X7R stimulation enhanced secretion } \\
\text { of proinflammatory cytokines }\end{array}$ & - & {$[172,173]$} \\
\hline Rats injected with 6-OHDA & - & $\begin{array}{l}\text { Inhibition of A2AR improved motor } \\
\text { performance and cognition }\end{array}$ & {$[174]$} \\
\hline $\begin{array}{l}\text { Rats injected with haloperidol } \\
\text { (DA antagonist) }\end{array}$ & - & $\begin{array}{l}\text { Inhibition of A2AR reversed locomotor } \\
\text { suppression and tremulous jaw movements }\end{array}$ & {$[174,175]$} \\
\hline
\end{tabular}

Alzheimer's disease (AD), P2X7 receptors (P2X7R), adenosine A2A receptor (A2AR), 6-hydroxydopamine (6-OHDA), and dopamine (DA).

TABle 4: Ectonucleotidases (E-NTPDase, E-5' -nucleotidase, and adenosine deaminase) in experimental models and patients with Alzheimer's disease (AD) and Parkinson's disease (PD).

\begin{tabular}{|c|c|c|c|c|c|}
\hline R Sample & E-NTPDase & E-5'-nucleotidase & $\begin{array}{l}\text { Adenosine } \\
\text { deaminase }\end{array}$ & $\begin{array}{c}\text { Alkaline } \\
\text { phosphatase } \\
\text { (TNAP) }\end{array}$ & Reference \\
\hline $\begin{array}{l}\text { Synaptosomes of rats injected } \\
\text { with scopolamine }\end{array}$ & $\begin{array}{c}\downarrow \text { enzymatic activity to ATP } \\
\text { (hippocampus and cortex) } \\
\downarrow \text { enzymatic activity to ADP } \\
\text { (hippocampus) }\end{array}$ & $\begin{array}{l}\downarrow \text { enzymatic activity } \\
\text { (hippocampus) }\end{array}$ & $\begin{array}{l}\downarrow \text { enzymatic activity } \\
\text { (hippocampus) }\end{array}$ & - & [169] \\
\hline $\begin{array}{l}\text { Synaptosomes of rats injected } \\
\text { with scopolamine }\end{array}$ & $\begin{array}{c}\uparrow \text { enzymatic activity to ATP } \\
\text { (hippocampus and cortex) } \\
\uparrow \text { enzymatic activity to ADP } \\
\text { (hippocampus) }\end{array}$ & $\begin{array}{l}\downarrow \text { enzymatic activity } \\
\text { (hippocampus) }\end{array}$ & $\begin{array}{c}\uparrow \text { enzymatic activity } \\
\text { (hippocampus) }\end{array}$ & - & {$[170]$} \\
\hline $\begin{array}{l}\text { Hippocampus and plasma } \\
\text { from patients with AD }\end{array}$ & - & - & - & $\begin{array}{l}\uparrow \text { enzymatic } \\
\text { activity }\end{array}$ & {$[171]$} \\
\hline Plasma from patients with $\mathrm{AD}$ & - & - & - & $\begin{array}{l}\uparrow \text { enzymatic } \\
\text { activity }\end{array}$ & {$[172,173]$} \\
\hline Serum from patients with PD & $\begin{array}{l}\uparrow \text { enzymatic activity to ATP } \\
\uparrow \text { enzymatic activity to ADP }\end{array}$ & - & - & - & {$[174]$} \\
\hline
\end{tabular}

Alzheimer's disease (AD) and Parkinson's disease (PD).

[152]. This event has been associated with increased TNAP expression and unbalances of the intracellular calcium homeostasis and phosphorylation levels of intracellular tau [153]. Increased TNAP levels in the plasma of the $A D$ patients have also been reported in literature [151, 154], suggesting that TNAP is a good biomarker of disease progression. On the other hand, the activity of the purinergic enzyme ADA did not present any significant differences in the serum of patients with $\mathrm{AD}$, compared to unaffected controls [155].

3.6. Parkinson's Disease. Parkinson's disease (PD) is considered the most frequent movement disorder. Clinically, "movement disorder" is defined by its cardinal motor symptoms: bradykinesia, rigidity, and tremor at rest [156]. Furthermore, most patients will also experience nonmotor symptoms that include mood, cognitive, speech, sensation, and sleep disturbances. The major cause of these symptoms is the progressive loss of dopaminergic neurons in the substantia nigra pars compacta projecting to the striatum, leading to a severe deficiency of dopamine in the putamen and the caudate nucleus. The neuropathological hallmark of PD is cytosolic Lewy bodies, which are characterized by aggregated $\alpha$-synuclein ( $\alpha$-Syn) [157].

Activated microglia is a common feature observed in individuals with neurodegenerative disorders, including PD, and it possibly contributes to neuronal death. Jiang et al. have shown that stimulation of the microglial P2X7 receptor by 
extracellular $\alpha$-Syn, with PI3K/AKT activation and increased oxidative stress, could be an important mechanism and a potential therapeutic target for PD [158]. Furthermore, release of ATP from disrupted cells might cause cell death in neighboring cell-expressing $\mathrm{P} 2 \mathrm{X} 7$ receptors, leading to a necrotic volume increase, which has also been implicated in the pathogenesis of PD [159]. Recently, several reports have suggested potential effects of the adenosine A2A receptor antagonist on cognitive dysfunction in $\operatorname{PD}[160,161]$. Indeed, in rodent models of $\mathrm{PD}, \mathrm{A} 2 \mathrm{~A}$ antagonism exerts antiparkinsonian actions [162-164]. Similarly, this treatment proved to be effective against experimentally induced tremor [165].

Despite several studies provide strong evidence that purinergic receptors are linked to the pathogenesis of PD, the evidence available on a potential involvement of purinergic enzymes is still very scarce. To date, we have only found a few articles concerning this issue. Medeiros et al. have studied the levels of ATP and the activity of the enzymes ADP E-

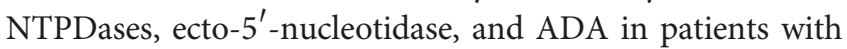
PD [166]. The results show higher E-NTPDase ATP/ADP activities in PD patients, suggesting an important inflammatory activity in this disease. Another study has analyzed the mRNA levels of E-NTPDase and E-5'-nucleotidase from striatal slices, in a unilaterally lesioned 6-OHDA rat model [167]. The classical method of intracerebral infusion of 6-OHDA involving a massive destruction of nigrostriatal dopaminergic neurons is largely used to investigate motor and biochemical dysfunctions in PD [168]. However, it was found no alteration in the mRNA levels of the enzymes tested [167] (Tables 3 and 4).

3.7. Multiple Sclerosis. Multiple sclerosis (MS) is a chronic inflammatory disease, of progressive character with relapsing-remitting phases, that represents the major disabling neurological illness of young adults [176]. This disease affects the myelin sheath of axons and is characterized by demyelination of neurons in the central and peripheral nervous system. Furthermore, the establishment of tissue oxidative stress associated with a neuroinflammatory process culminates in the loss of myelin content and subsequent death of oligodendrocytes and Schwann cells [177, 178].

The mechanisms implicated in the pathogenesis of MS include autoimmunity, inflammation, demyelination, and neurodegeneration. Since the beginning of demyelination processes, the appearance of multiple plates in the white matter of brain and spinal cord can occur [179]. These lesions lead to the disability or complete loss of nerve impulses that result in the appearance of clinical manifestations such as motor impairment [180], blurred vision, hyperalgesia in the upper and lower limbs, excessive tiredness, weakness, anxiety, depression, and irreversible neurological deficits $[179,181,182]$. The remission is a subsequent phase characterized by the remyelination and tissue repair, with partial or complete disappearance of symptoms [176].

The relationship between inflammation and degeneration during the progression of MS is due to successive outbreaks and remissions. There is a higher frequency of events accompanied inflammatory demyelination of the white matter and damage to axons. In this step, it is possible to tissue repair capacity in which there is a remyelination and axonal in the disappearance of clinical manifestations. As these events are repeated, the tissue recovery becomes ineffective. The secondary progressive phase initiates with the establishment of neurodegenerative tissue followed by cerebral gray matter atrophy. At this stage, there is a progressive increase over the score disabilities that can lead to incapacitation of the patient [183].

The MS does not have etiology and cure defined. Therefore, several types of animal models that produce demyelination have been used for scientific research, in order to discover pharmacological tools for assessing compounds as potential drugs or search for evidence of cellular mechanisms to better understand this disease. Among these, it is possible to highlight the chemically induced CNS lesions, such as those generated with cuprizone feeding, ethidium bromide injection, and lysolecithin, or the experimental autoimmune encephalomyelitis (EAE) model, widely used in drug screening as it most faithfully represents the pathology seen in MS [184]. As described by Merrill, the advantages of these models are the dissociation of the demyelination event, from the complexities introduced into the tissue pathology by chronic inflammatory cells and their soluble mediators, reproducibly timed spontaneous remyelination, and robust demyelination and remyelination in anatomically distinct areas facilitating focused, quantitative assessment of lesion generation and repair [185-187].

Recent reports have highlighted the association between receptors and signaling molecules of the purinergic system with demyelinating diseases, including MS [188-191]. Furthermore, ATP and adenosine also play a significant role in the pathophysiology of numerous acute and chronic disorders that include events related with CNS demyelination and remyelination [23, 192-194].

Over the last decade, the ectonucleotidases have become target of study by modulating purinergic signaling and contributing to the fine-tuning of inflammatory and immune responses. The overwhelming evidence indicates that extracellular ATP acting through specific cell surface receptors is involved in proinflammatory functions such as stimulation and proliferation of lymphocytes and microglial cell and cytokine production and secretion [195, 196]. However, its breakdown product, adenosine, exhibits potent anti-inflammatory and immunosuppressive action by inhibiting proliferation of $\mathrm{T}$ cells and secretion of cytokines [197, 198].

The association of the purinergic receptors in the demyelinating diseases has been explored in some previously published studies $[199,200]$. An overview of the main findings relating the purinoreceptors with MS in experimental models and postmortem tissue of humans with this pathology can be found in Table 5 .

Based on the evidence reported in Table 2, the four purinergic receptors especially known to be involved in MS are $\mathrm{P} 2 \mathrm{X} 7, \mathrm{P} 2 \mathrm{Y} 12, \mathrm{~A} 1$, and $\mathrm{A} 2 \mathrm{~A}$ receptors. Although the role of purinoreceptors is not well elucidated, it is important to note that the number of published evidence and studies for MS is superior to investigations into the role of 
TABLE 5: Role of purinoreceptors in experimental models and patients with MS: overview of main findings.

Sample
$\begin{aligned} & \text { Cerebral cortex from healthy and MS } \\ & \text { patients }\end{aligned}$

Receptors

Reduction in the P2Y12R is immunoreactive in the lesions. This

P2Y12 receptor event was directly correlated with the extent demyelination found Reference in grey matter cortical and subcortical white matter.

P2X7R is highly expressed in microglia in MS lesions during the peak of EAE. P2X7R is associated with a proinflammatory phenotype of human microglia. In parallel, P2Y12R was

Tissues of rats exposed to EAE model and P2X7 receptor brain tissue from healthy and MS patients P2Y12 receptor associated with an anti-inflammatory phenotype in human microglia. P2Y12R was expressed at lower levels in active inflammatory MS lesions. P2Y12R expression increased in the remission phase of EAE.

Coculture of $\mathrm{P} 2 \mathrm{X} 7 \mathrm{R}^{-1-}$ macrophages with wild-type lymphocytes showed that enhanced proliferative activity resided within the Spleen and lymph node cell from P2X7R $\mathrm{R}^{-/-}$P2X7 receptor $\quad$ P2X7R $\mathrm{R}^{-1-}$ lymphocyte population. Furthermore, mRNA and mice exposed to EAE model
p $2 X 7$ receptor protein for IFN- $\gamma$ were significantly reduced in the CNS of
P2X7R $\mathrm{R}^{-1-}$ mice with EAE. Enhanced susceptibility of P2X7R $\mathrm{R}^{-/-}$ mice to EAE reflects a loss of apoptotic activity in lymphocytes.

Investigation of the role of the A1 receptor using antagonists.

Caffeine $(10-30 \mathrm{~m} / \mathrm{kg})$ decreases the incidence of EAE and attenuates EAE pathology at behavioral, histological

EAE induced in rats by guinea pig spinal cord homogenates (GPSCH model)

A1 receptor (inflammatory cell infiltration and demyelination), and neurochemical (expression of inflammatory cytokines) levels. In addition, caffeine also upregulated A1 receptor and TGF- $\beta$ mRNAs and suppressed INF- $\gamma$ mRNA in EAE rats.

Brain of female Lewis rats exposed to EAE model

P2X7 receptor

Enhanced expression of GFAP and S100 $\beta$ is associated with expression of P2X7R. Brilliant blue G, an antagonist of P2X7R, significantly decreases astrogliosis (GFAP and S100 $\beta$ ).

The enhancement in the expression of the P2X7 receptor at the Brain of rats exposed to EAE model $\quad$ P2X7 receptor $\begin{gathered}\text { level of both mRNA and protein was observed in the peak of } \\ \text { neurological symptoms and was connected mostly with neurons }\end{gathered}$ $(4,6,8$, and 10 days postimmunization). Human monocytes from Australasian
patients with MS
P2X7 receptor A rare P2X7 variant Arg307Gln with absent pore formation
function protects against neuroinflammation in MS.

Upregulation of A2AR in the CNS in EAE, predominantly detected on $\mathrm{T}$ cells and macrophages/microglia. A preventive EAE treatment with A2AR-specific agonist inhibited myelin-specific T cell proliferation ex vivo and ameliorated disease. In parallel, the application of the same agonist after disease onset exacerbated nonremitting EAE progression and resulted in more severe tissue destruction. A2AR-deficient mice showed accelerated and exacerbated disease manifestation with higher numbers of inflammatory lesions in the early stage. EAE quickly ameliorated and myelin debris accumulation was lower in $\mathrm{A}_{2} \mathrm{AR}^{-1-}$ mice.

Finally, an in vitro activation of A2AR inhibited phagocytosis of myelin by macrophages and primary microglia as well as migration of $\mathrm{CD}^{+} \mathrm{T}$ cells, macrophages, and primary microglia.

CGS21680 (CGS, A2AR agonist) significantly suppressed specific lymphocyte proliferation, reduced infiltration of $\mathrm{CD} 4^{+} \mathrm{T}$ lymphocytes, and attenuated the expression of inflammatory

Lymphocyte isolation from nerve tissue and lumbar spinal cord of female mice exposed to EAE

A2A receptor cytokines, which in turn inhibited the EAE progression. CGS can increase the $\left[\mathrm{Ca}^{+}\right] \mathrm{i}$ in murine lymphocytes, which may be the mechanism underlying the suppressive effects of CGS-induced A2AR activation on EAE progression.

Sustained activation of P2X7R in vivo causes lesions that are reminiscent of the major features of MS plaques (demyelination, oligodendrocyte death, and axonal damage). In addition, treatment with P2X7R antagonists reduces demyelination and ameliorates the associated neurological symptoms. The study
Oligodendrocyte cultures and postmortem
optic nerve samples from MS patients 
TABLE 5: Continued.

\begin{tabular}{|c|c|c|c|}
\hline Sample & Receptors & Main findings & Reference \\
\hline & & $\begin{array}{l}\text { suggests that ATP can kill oligodendrocytes via P2X7R activation } \\
\text { and this process contributes to EAE. Importantly, P2X7R } \\
\text { expression is elevated in normal-appearing axon tracts in } \\
\text { MS patients. }\end{array}$ & \\
\hline $\begin{array}{l}\text { Peripheral blood mononuclear cells from } \\
\text { MS patients }\end{array}$ & Al receptor & $\begin{array}{l}\text { Decreased levels of adenosine and its A1 receptor modulate TNF } \alpha \\
\text { and IL-6 levels and may contribute to the pathogenesis of MS. }\end{array}$ & [210] \\
\hline $\begin{array}{l}\text { Brain and spinal cord of female SJL/J mice } \\
\text { infected with Theiler's virus infection }\end{array}$ & A2A receptor & $\begin{array}{l}\text { A2A receptors participate in anti-inflammatory effects of } \\
\text { cannabidiol. A2A antagonist ZM241385 partially blocks } \\
\text { the protective effects of cannabidiol in the initial stages } \\
\text { of inflammation. }\end{array}$ & {$[211]$} \\
\hline Human microglia & $\mathrm{P} 2 \mathrm{Y} 12$ receptor & $\begin{array}{l}\text { P2Y12 is expressed on parenchymal microglia and is stable } \\
\text { throughout human brain development, including fetal phases. MS } \\
\text { result in decreased P2Y12 immunoreactivity in plaque- or lesion- } \\
\text { associated myeloid cells. P2Y12 is a useful marker for the } \\
\text { identification of human microglia throughout the lifespan. }\end{array}$ & [212] \\
\hline Blood from MS patients & $\begin{array}{l}\mathrm{P} 2 \mathrm{X} 4 \text { receptor } \\
\mathrm{P} 2 \mathrm{X} 7 \text { receptor }\end{array}$ & $\begin{array}{l}\text { A rare genetic variant in P2RX4 and P2RX7 is a major genetic } \\
\text { contributor to disease (description of the three variant haplotypes: } \\
\text { P2RX7 rs140915863:C>T [p.T205M]; P2RX7 rs201921967:A>G } \\
\text { [p.N361S]; and P2RX4 rs765866317:G>A [p.G135S]). }\end{array}$ & [213] \\
\hline $\begin{array}{l}\text { C57BL6 mice and P2X7-deficient mice } \\
\text { exposed to EAE model }\end{array}$ & $\mathrm{P} 2 \mathrm{X} 7$ receptor & $\begin{array}{l}\text { The incidence of EAE disease in P2X7 mice was reduced 4-fold } \\
\text { compared to the wild type. Mouse splenic T cells isolated from } \\
\text { P2X7 null mice produced greater IFN } \gamma \text { and IL-17 (from 3- to } \\
\text { 12-fold greater levels) than wild-type cells. Although infiltrating } \\
\text { cells were detected in the brains of both the P2X7 and wild type, } \\
\text { astroglial activation and axonal damage were reduced compared } \\
\text { to wild type. }\end{array}$ & {$[214]$} \\
\hline $\begin{array}{l}\text { Brain and spinal cord from female mice } \\
\text { exposed to EAE model }\end{array}$ & A1A receptor & 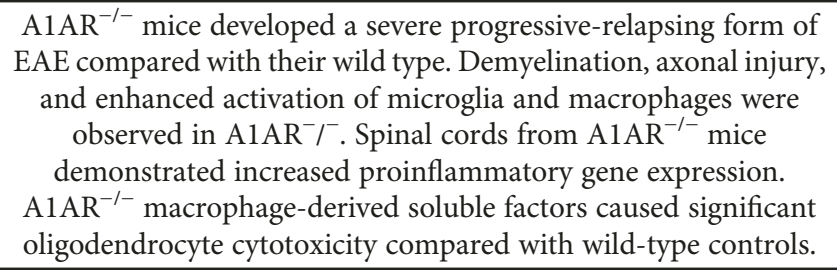 & [215] \\
\hline Spinal cord from MS patients & $\mathrm{P} 2 \mathrm{X} 7$ receptor & $\begin{array}{c}\text { In control spinal cord, few small microglial cells/macrophages } \\
\text { were scattered throughout the tissue. However, MS specimens had } \\
\text { significantly greater density of such cells with longer processes } \\
\text { in affected regions. MS also had significantly greater density of } \\
\text { P2X7 and immunoreactive microglial cells/macrophages in } \\
\text { affected regions. }\end{array}$ & [216] \\
\hline
\end{tabular}

MS (multiple sclerosis), experimental autoimmune encephalomyelitis (EAE), central nervous system (CNS), and glial fibrillary acid protein (GFAP).

ectonucleotidases in this pathology. In this way, in Table 2, we also reviewed the activity and expression of ectonucleotidase enzymes ecto-NTPDase, E- 5 ' -nucleotidase, and adenosine deaminase in experimental models and in patients with MS (see Table 6).

\section{Conclusions}

The main causes of death and sickness around the world have changed significantly in the last years, with chronic neurologic and degenerative diseases becoming more and more important. Several evidences show that purinergic signaling system is involved in processes associated with health and disease. In this way, the role of the purinergic receptors in the pathophysiology of different degenerative diseases has been extensively studied. However, the role of the purinergic system enzymes is not fully understood yet. This review summarizes the most current knowledge on the role of families of nucleotide metabolizing enzymes, the ectonucleotidases, on degenerative diseases. Considerable attention was directed towards diseases related to the cardiovascular system (atherosclerosis and hypertension) and central nervous system (epilepsy, Alzheimer's disease, Parkinson's disease, and multiple sclerosis). Firstly, it has been shown that a reduction in the activity of ectonucleotidases can be associated with progression of arteriosclerosis. Furthermore, high expression and activity of CD73 and E-NTPDase 1 may have beneficial effects contributing to the production of extracellular adenosine. In parallel, the low expression and activity of ADA are an alternative maintenance of levels of adenosine, 
TABle 6: Ectonucleotidases (E-NTPDase, E-5'-nucleotidase, and ADA) in experimental models and patients with MS: a review.

\begin{tabular}{|c|c|c|c|c|}
\hline Sample & E-NTPDase & E- $5^{\prime}$-nucleotidase & $\begin{array}{l}\text { Adenosine } \\
\text { deaminase }\end{array}$ & Reference \\
\hline Serum of MS patients (RRMS form) & - & - & $\uparrow$ enzymatic activity & [169] \\
\hline Lymphocytes of MS patients (RRMS form) & $\begin{array}{c}\uparrow \text { expression CD39 } \\
\uparrow \text { enzymatic activity to ATP } \\
\text { and ADP }\end{array}$ & - & $\downarrow$ enzymatic activity & {$[170]$} \\
\hline Platelets of MS patients (RRMS form) & $\begin{array}{l}\downarrow \text { enzymatic activity to ATP } \\
\text { and ADP }\end{array}$ & $\downarrow$ enzymatic activity & $\downarrow$ enzymatic activity & {$[171]$} \\
\hline Platelets from rats demyelinated with EB & $\begin{array}{c}\downarrow \text { enzymatic activity to ATP } \\
\text { (on days } 3,7,15 \text {, and } 21 \text { ) } \\
\downarrow \text { enzymatic activity to ADP } \\
\text { (on day } 7 \text { ) }\end{array}$ & $\begin{array}{l}\downarrow \text { enzymatic activity } \\
\quad \text { (on day 15) }\end{array}$ & - & {$[172,173]$} \\
\hline Platelets from rats demyelinated with EB & $\begin{array}{l}\uparrow \text { enzymatic activity to ATP } \\
\text { (on day } 7 \text { ) } \\
\uparrow \text { enzymatic activity to ADP } \\
\text { (on day } 7 \text { ) }\end{array}$ & $\begin{array}{l}\uparrow \text { enzymatic activity } \\
\text { (on day7) }\end{array}$ & - & {$[174]$} \\
\hline $\begin{array}{l}\text { Synaptosomes from cerebral cortex of rats } \\
\text { demyelinated with EB }\end{array}$ & $\begin{array}{l}\uparrow \text { enzymatic activity to ATP } \\
\text { (on days } 7 \text { and 15) } \\
\uparrow \text { enzymatic activity to ADP } \\
\text { (on day } 7 \text { ) }\end{array}$ & $\begin{array}{l}\uparrow \text { enzymatic activity } \\
\text { (on day 7) }\end{array}$ & - & {$[174,175]$} \\
\hline $\begin{array}{l}\text { Plasma membrane from lumbosacral region of spinal } \\
\text { cords from EAE-induced rats }\end{array}$ & $\begin{array}{c}\uparrow \text { enzymatic activity to ATP } \\
\text { (on days } 7,15 \text {, and } 25 \text { ) } \\
\uparrow \text { enzymatic activity to ADP } \\
\text { (on day } 15 \text { ) }\end{array}$ & $\begin{array}{l}\uparrow \text { enzymatic activity } \\
\text { (on days } 15 \text { and } 25 \text { ) }\end{array}$ & - & [217] \\
\hline Blood serum from EAE-induced rats & $\begin{array}{l}\uparrow \text { enzymatic activity to ATP } \\
\quad \text { (on day 25) } \\
\downarrow \text { enzymatic activity to ADP } \\
\text { (on days } 15 \text { and } 25 \text { ) }\end{array}$ & $\begin{array}{l}\downarrow \text { enzymatic activity } \\
\quad \text { (on day 15) }\end{array}$ & - & [217] \\
\hline $\mathrm{T}$ cells from patients with relapsing-remitting MS & $\begin{array}{l}\downarrow \text { in number of CD39- } \\
\text { positive Treg cells }\end{array}$ & - & - & {$[218,219]$} \\
\hline
\end{tabular}

EB (ethidium bromide), relapsing-remitting multiple sclerosis (RRMS), experimental autoimmune encephalomyelitis (EAE), and Treg (regulatory T cells).

in order to increase antithrombotic and anti-inflammatory effects. In relation to hypertension, a suppression of ENTPDase 1 is linked to the pathogenesis of this disease and an increase in the activity of ectonucleotidases was reported in animal models of hypertension and in human. On the other hand, $\mathrm{P} 2$ receptor modulation seems to be a promising tool for a novel therapeutic approach for epilepsy. Lastly, a reduction of ATP levels in experimental models for $\mathrm{AD}$ and increase in the ectonucleotidases activities, especially ENTPDase in patients with Parkinson's disease and multiple sclerosis, were found.

In conclusion, we verified that the activity and expression of the ectonucleotidases investigated in this review may be altered in some degenerative diseases. Taken together, the data discussed in this paper collaborate for a better understanding of the molecular mechanisms involved in these highly complex diseases, suggesting a number of directions for future research. In fact, more studies should be conducted to better understand the changes in metabolism and maintenance of adenine nucleotide and nucleoside levels in degenerative diseases. In addition, the study of the ectonucleotidase role may contribute to a better understanding of the molecular mechanisms of highly complex diseases and with major impact on patients' quality of life.

\section{Future Prospects}

Ectonucleotidases are nucleotide-metabolizing enzymes and play an essential role in regulating and controlling extracellular nucleotides. These nucleotides and nucleosides are responsible for the well functioning of normal cells. A wrong signaling mediated by these molecules triggers pathophysiological disorders like as atherosclerosis, hypertension, cancer, epilepsy, Alzheimer's disease, Parkinson's disease and multiple sclerosis. In this way, understanding the role of these molecules can be an important key factor to discover pharmacological targets and mechanisms that minimize deleterious effects of these diseases.

Until now, the investigations describes which ectonucleotidases have their activity or expression changes in different biological tissues in experimental models and patients with the pathologies reviewed in this study. From these findings, the next step is to know how the catabolic activity of ectonucleotidases can regulate the production of proinflammatory mediators and the immune response, both physiologically and pathologically.

Evidences have pointed out the important role of inhibitors of ectonucleotidases, highlighting their potential as novel drugs [220-222]. It is suggested that inhibitors of 
ectonucleotidases might be an ideal drug target for many therapeutic applications such as anticancer and immunomodulatory for the treatment of central nervous system disorders and cardiovascular diseases [220]. An important perspective would be to explore the use of these drugs in experimental biology. Such investigations would reveal whether up- or downregulation of the ectonucleotidases would restore immune markers and physiological functions compromised in experimental models and cell cultures. Since inhibitors of ectonucleotidases might be an ideal drug target for many therapeutic applications such as anticancer and immunomodulatory for the treatment of central nervous system disorders and cardiovascular diseases [220], more research is needed to elucidate the role of these enzymes in these pathologies and their role potential targets for drug discovery.

\section{Conflicts of Interest}

All authors report no conflicts of interest.

\section{References}

[1] E. K. Zuba-Surma, W. Wojakowski, Z. Madeja, and M. Z. Ratajczak, "Stem cells as a novel tool for drug screening and treatment of degenerative diseases," Current Pharmaceutical Design, vol. 18, no. 18, pp. 2644-2656, 2012.

[2] R. P. Zhou, X. S. Wu, Z. S. Wang, Y. Y. Xie, J. F. Ge, and F. H. Chen, "Novel insights into acid-sensing ion channels: implications for degenerative diseases," Aging and Disease, vol. 7, no. 4, pp. 491-501, 2016.

[3] M. Cieślak, J. Czarnecka, and K. Roszek, "The roles of purinergic signaling in psychiatric disorders," Acta Biochimica Polonica, vol. 63, no. 1, pp. 1-9, 2016.

[4] G. G. Yegutkin, "Enzymes involved in metabolism of extracellular nucleotides and nucleosides: functional implications and measurement of activities," Critical Reviews in Biochemistry and Molecular Biology, vol. 49, no. 6, pp. 473-497, 2014.

[5] S. C. Robson, J. Sévigny, and H. Zimmermann, "The ENTPDase family of ectonucleotidases: structure function relationships and pathophysiological significance," Purinergic Signalling, vol. 2, no. 2, pp. 409-430, 2006.

[6] H. Zimmermann, "Ectonucleotidases: some recent developments and a note on nomenclature," Drug Development Research, vol. 52, no. 1-2, pp. 44-56, 2001.

[7] A. N. Drury and A. Szent-Györgyi, "The physiological activity of adenine compounds with especial reference to their action upon the mammalian heart," The Journal of Physiology, vol. 68, no. 3, pp. 213-237, 1929.

[8] G. Burnstock, "Historical review: ATP as a neurotransmitter," Trends in Pharmacological Sciences, vol. 27, no. 3, pp. 166-176, 2006.

[9] G. Burnstock, "Pathophysiology and therapeutic potential of purinergic signaling," Pharmacological Reviews, vol. 58, no. 1, pp. 58-86, 2006.

[10] G. Burnstock, "Purinergic regulation of vascular tone and remodelling," Autonomic and Autacoid Pharmacology, vol. 29, no. 3, pp. 63-72, 2009.

[11] G. Burnstock, G. Campbell, D. Satchell, and A. Smythe, "Evidence that adenosine triphosphate or a related nucleotide is the transmitter substance released by non-adrenergic inhibitory nerves in the gut," British Journal of Pharmacology, vol. 40, no. 4, pp. 668-688, 1970.

[12] K. Puchalowicz, I. Baranowska-Bosiacka, V. Dziedziejko, and D. Chlubek, "Purinergic signaling and the functioning of the nervous system cells," Cellular and Molecular Biology Letters, vol. 20, no. 5, pp. 867-918, 2015.

[13] G. Burnstock, "Purinergic nerves," Pharmacological Reviews, vol. 24, no. 3, pp. 509-581, 1972.

[14] G. Burnstock, "Physiology and pathophysiology of purinergic neurotransmission," Physiological Reviews, vol. 87, no. 2, pp. 659-797, 2007.

[15] B. Roy, A. Depaix, C. Perigaud, and S. Peyrottes, "Recent trends in nucleotide synthesis," Chemical Reviews, vol. 116, no. 14, pp. 7854-7897, 2016.

[16] G. Burnstock, G. E. Knight, and A. V. H. Greig, "Purinergic signaling in healthy and diseased skin," Journal of Investigative Dermatology, vol. 132, no. 3, Part 1, pp. 526-546, 2012.

[17] H. Kettenmann, U. K. Hanisch, M. Noda, and A. Verkhratsky, "Physiology of microglia," Physiological Reviews, vol. 91, no. 2, pp. 461-553, 2011.

[18] L. T. Bune, J. R. Larsen, P. Thaning, N. E. Bune, P. Rasmussen, and J. B. Rosenmeier, "Adenosine diphosphate reduces infarct size and improves porcine heart function after myocardial infarct," Physiological Reports, vol. 1, no. 1, article e00003, 2013.

[19] G. Burnstock and C. Kennedy, "Is there a basis for distinguishing two types of P2-purinoceptor?," General Pharmacology: The Vascular System, vol. 16, no. 5, pp. 433-440, 1985.

[20] M. P. Abbracchio and G. Burnstock, "Purinoceptors: are there families of P2X and P2Y purinoceptors?," Pharmacology \& Therapeutics, vol. 64, no. 3, pp. 445-475, 1994.

[21] M. P. Abbracchio, G. Burnstock, A. Verkhratsky, and H. Zimmermann, "Purinergic signalling in the nervous system: an overview," Trends in Neurosciences, vol. 32, no. 1, pp. 19-29, 2009.

[22] G. R. Dubyak, "Go it alone no more-P2X7 joins the society of heteromeric ATP-gated receptor channels," Molecular Pharmacology, vol. 72, no. 6, pp. 1402-1405, 2007.

[23] M. Tewari and P. Seth, "Emerging role of P2X7 receptors in CNS health and disease," Ageing Research Reviews, vol. 24, Part B, pp. 328-342, 2015.

[24] J. D. Brederson and M. F. Jarvis, "Homomeric and heteromeric P2X3 receptors in peripheral sensory neurons," Current Opinion in Investigational Drugs, vol. 9, no. 7, pp. 716-725, 2008.

[25] M. Monif, C. A. Reid, K. L. Powell, M. L. Smart, and D. A. Williams, "The P2X7 receptor drives microglial activation and proliferation: a trophic role for P2X7R pore," Journal of Neuroscience, vol. 29, no. 12, pp. 3781-3791, 2009.

[26] A. Jimenez-Pacheco, M. Diaz-Hernandez, M. ArribasBlazquez et al., "Transient $\mathrm{P} 2 \mathrm{X} 7$ receptor antagonism produces lasting reductions in spontaneous seizures and gliosis in experimental temporal lobe epilepsy," The Journal of Neuroscience, vol. 36, no. 22, pp. 5920-5932, 2016.

[27] L. Alves, J. da Silva, D. Ferreira et al., "Structural and molecular modeling features of P2X receptors," International Journal of Molecular Sciences, vol. 15, no. 3, pp. 4531-4549, 2014.

[28] N. P. Barrera, S. J. Ormond, R. M. Henderson, R. D. MurrellLagnado, and J. M. Edwardson, "Atomic force microscopy imaging demonstrates that $\mathrm{P} 2 \mathrm{X}_{2}$ receptors are trimers but 
that $\mathrm{P} 2 \mathrm{X}_{6}$ receptor subunits do not oligomerize," Journal of Biological Chemistry, vol. 280, no. 11, pp. 10759-10765, 2005.

[29] G. Burnstock, "Physiopathological roles of P2X receptors in the central nervous system," Current Medicinal Chemistry, vol. 22, no. 7, pp. 819-844, 2015.

[30] D. Donnelly-Roberts, S. McGaraughty, C. C. Shieh, P. Honore, and M. F. Jarvis, "Painful purinergic receptors," Journal of Pharmacology and Experimental Therapeutics, vol. 324, no. 2, pp. 409-415, 2008.

[31] A. Franceschini and E. Adinolfi, "P2X receptors: new players in cancer pain," World Journal of Biological Chemistry, vol. 5, no. 4, pp. 429-436, 2014.

[32] G. Burnstock and G. E. Knight, "Cellular distribution and functions of P2 receptor subtypes in different systems," International Review of Cytology, vol. 240, pp. 31-304, 2004.

[33] M. P. Abbracchio, G. Burnstock, J. M. Boeynaems et al., "International Union of Pharmacology LVIII: update on the P2Y G protein-coupled nucleotide receptors: from molecular mechanisms and pathophysiology to therapy," Pharmacological Reviews, vol. 58, no. 3, pp. 281-341, 2006.

[34] G. A. Weisman, L. T. Woods, L. Erb, and C. I. Seye, "P2Y receptors in the mammalian nervous system: pharmacology, ligands and therapeutic potential," CNS \& Neurological Disorders - Drug Targets, vol. 11, no. 6, pp. 722-738, 2012.

[35] R. D. Fields and G. Burnstock, "Purinergic signalling in neuron-glia interactions," Nature Reviews Neuroscience, vol. 7, no. 6, pp. 423-436, 2006.

[36] T. Engel, M. Alves, C. Sheedy, and D. C. Henshall, "ATPergic signalling during seizures and epilepsy," Neuropharmacology, vol. 104, pp. 140-153, 2016.

[37] S. P. Colgan, H. K. Eltzschig, T. Eckle, and L. F. Thompson, "Physiological roles for ecto-5'-nucleotidase (CD73)," Purinergic Signalling, vol. 2, no. 2, pp. 351-360, 2006.

[38] F. Di Virgilio, "Purines, purinergic receptors, and cancer," Cancer Research, vol. 72, no. 21, pp. 5441-5447, 2012.

[39] B. A. Evans, C. Elford, A. Pexa et al., "Human osteoblast precursors produce extracellular adenosine, which modulates their secretion of IL-6 and osteoprotegerin," Journal of Bone and Mineral Research, vol. 21, no. 2, pp. 228-236, 2006.

[40] I. C. Iser, P. A. Bracco, C. E. I. Gonçalves et al., "Mesenchymal stem cells from different murine tissues have differential capacity to metabolize extracellular nucleotides," Journal of Cellular Biochemistry, vol. 115, no. 10, pp. 1673-1682, 2014.

[41] J. Linden, "Adenosine in tissue protection and tissue regeneration," Molecular Pharmacology, vol. 67, no. 5, pp. 1385-1387, 2005.

[42] K. A. Jacobson and Z. G. Gao, "Adenosine receptors as therapeutic targets," Nature Reviews Drug Discovery, vol. 5, no. 3, pp. 247-264, 2006.

[43] F. Di Virgilio and E. Adinolfi, "Extracellular purines, purinergic receptors and tumor growth," Oncogene, vol. 36, no. 3, pp. 293-303, 2017.

[44] S. A. Rivkees, "Localization and characterization of adenosine receptor expression in rat testis," Endocrinology, vol. 135, no. 6, pp. 2307-2313, 1994.

[45] S. James, P. J. Richardson, and J. H. Xuereb, "Characterization and localization of the high affinity adenosine A2 receptor in rat and human brain," Biochemical Society Transactions, vol. 19, no. 1, p. 7S, 1991.
[46] M. F. Jarvis, "Characterization of P1 (adenosine) purinoceptors," Current Protocols in Pharmacology, vol. 62, pp. 1.9.1-1.9.16, 2013.

[47] J. Maiuolo, F. Oppedisano, S. Gratteri, C. Muscoli, and V. Mollace, "Regulation of uric acid metabolism and excretion," International Journal of Cardiology, vol. 213, pp. 8-14, 2016.

[48] H. Zimmermann, "Ectonucleotidases in the nervous system," in Purinergic Signalling in Neuron-Glia Interactions: Novartis Foundation Symposium 276, Novartis Foundation Symposia, pp. 113-130, 2008.

[49] A. M. Cardoso, M. R. C. Schetinger, P. Correia-de-Sá, and J. Sévigny, "Impact of ectonucleotidases in autonomic nervous functions," Autonomic Neuroscience, vol. 191, pp. 25-38, 2015.

[50] H. Zimmermann, "Purinergic signaling in neural development," Seminars in Cell \& Developmental Biology, vol. 22, no. 2, pp. 194-204, 2011.

[51] V. Ralevic, "Purines as neurotransmitters and neuromodulators in blood vessels," Current Vascular Pharmacology, vol. 7, no. 1, pp. 3-14, 2009.

[52] L. Antonioli, R. Colucci, C. La Motta et al., "Adenosine deaminase in the modulation of immune system and its potential as a novel target for treatment of inflammatory disorders," Current Drug Targets, vol. 13, no. 6, pp. 842862, 2012.

[53] A. Cortes, E. Gracia, E. Moreno et al., "Moonlighting adenosine deaminase: a target protein for drug development," Medicinal Research Reviews, vol. 35, no. 1, pp. 85-125, 2015.

[54] G. L. Weiss and L. E. Lonnquist, Sociology of Health, Healing, and Illness, vol. 8th, World Health Statistics, 2015.

[55] B. B. Kelly and V. Fuster, Promoting Cardiovascular Health in the Developing World: A Critical Challenge to Achieve Global Health, National Academies Press, 2010.

[56] C. E. Stafstrom and L. Carmant, "Seizures and epilepsy: an overview for neuroscientists," Cold Spring Harbor Perspectives in Medicine, vol. 5, no. 6, 2015.

[57] J. Campisi, J. K. Andersen, P. Kapahi, and S. Melov, "Cellular senescence: a link between cancer and age-related degenerative disease?," Seminars in Cancer Biology, vol. 21, no. 6, pp. 354-359, 2011.

[58] C. G. Glabe, "Common mechanisms of amyloid oligomer pathogenesis in degenerative disease," Neurobiology of Aging, vol. 27, no. 4, pp. 570-575, 2006.

[59] V. N. Mutafova-Yambolieva and L. Durnin, “The purinergic neurotransmitter revisited: a single substance or multiple players?," Pharmacology \& Therapeutics, vol. 144, no. 2, pp. 162-191, 2014.

[60] G. Burnstock, "Purinergic signalling and disorders of the central nervous system," Nature Reviews Drug Discovery, vol. 7, no. 7, pp. 575-590, 2008.

[61] G. Burnstock and I. Novak, "Purinergic signalling and diabetes," Purinergic Signalling, vol. 9, no. 3, pp. 307-324, 2013.

[62] D. Ferrari, L. Vitiello, M. Idzko, and A. la Sala, "Purinergic signaling in atherosclerosis," Trends in Molecular Medicine, vol. 21, no. 3, pp. 184-192, 2015.

[63] G. Burnstock, "Purinergic signalling and endothelium," Current Vascular Pharmacology, vol. 14, no. 2, pp. 130145, 2016. 
[64] L. Koles, S. Furst, and P. Illes, "P2X and P2Y receptors as possible targets of therapeutic manipulations in CNS illnesses," Drug News \& Perspectives, vol. 18, no. 2, pp. 85-101, 2005.

[65] L. T. Woods, D. Ajit, J. M. Camden, L. Erb, and G. A. Weisman, "Purinergic receptors as potential therapeutic targets in Alzheimer's disease," Neuropharmacology, vol. 104, pp. 169-179, 2016.

[66] G. Burnstock, "Purinergic signalling: from discovery to current developments," Experimental Physiology, vol. 99, no. 1, pp. 16-34, 2014.

[67] M. Alves, R. Gomez-Villafuertes, N. Delanty et al., "Expression and function of the metabotropic purinergic P2Y receptor family in experimental seizure models and patients with drug-refractory epilepsy," Epilepsia, vol. 58, no. 9, pp. 1603-1614, 2017.

[68] J. A. Ribeiro, A. M. Sebastiao, and A. de Mendonca, "Adenosine receptors in the nervous system: pathophysiological implications," Progress in Neurobiology, vol. 68, no. 6, pp. 377-392, 2002.

[69] R. Lozano, M. Naghavi, K. Foreman et al., "Global and regional mortality from 235 causes of death for 20 age groups in 1990 and 2010: a systematic analysis for the Global Burden of Disease Study 2010," The Lancet, vol. 380, no. 9859, pp. 2095-2128, 2012.

[70] Y. Kanthi, M. C. Hyman, H. Liao et al., "Flow-dependent expression of ectonucleotide tri(di)phosphohydrolase-1 and suppression of atherosclerosis," Journal of Clinical Investigation, vol. 125, no. 8, pp. 3027-3036, 2015.

[71] D. Nam, C. W. Ni, A. Rezvan et al., "Partial carotid ligation is a model of acutely induced disturbed flow, leading to rapid endothelial dysfunction and atherosclerosis," American Journal of Physiology-Heart and Circulatory Physiology, vol. 297, no. 4, pp. H1535-H1543, 2009.

[72] J. Dunn, H. Qiu, S. Kim et al., "Flow-dependent epigenetic DNA methylation regulates endothelial gene expression and atherosclerosis," Journal of Clinical Investigation, vol. 124, no. 7, pp. 3187-3199, 2014.

[73] Y. M. Kanthi, N. R. Sutton, and D. J. Pinsky, "CD39: interface between vascular thrombosis and inflammation," Current Atherosclerosis Reports, vol. 16, no. 7, p. 425, 2014.

[74] J. Sevigny, F. P. Levesque, G. Grondin, and A. R. Beaudoin, "Purification of the blood vessel ATP diphosphohydrolase, identification and localisation by immunological techniques," Biochimica et Biophysica Acta (BBA) - General Subjects, vol. 1334, no. 1, pp. 73-88, 1997.

[75] J. Sevigny, C. Sundberg, N. Braun et al., "Differential catalytic properties and vascular topography of murine nucleoside triphosphate diphosphohydrolase 1 (NTPDase1) and NTPDase2 have implications for thromboregulation," Blood, vol. 99, no. 8, pp. 2801-2809, 2002.

[76] G. Kauffenstein, A. Drouin, N. Thorin-Trescases et al., "NTPDase1 (CD39) controls nucleotide-dependent vasoconstriction in mouse," Cardiovascular Research, vol. 85, no. 1, pp. 204-213, 2010.

[77] G. Kauffenstein, C. R. Furstenau, P. D'Orleans-Juste, and J. Sevigny, "The ecto-nucleotidase NTPDase1 differentially regulates $\mathrm{P} 2 \mathrm{Y} 1$ and $\mathrm{P} 2 \mathrm{Y} 2$ receptor-dependent vasorelaxation," British Journal of Pharmacology, vol. 159, no. 3, pp. 576-585, 2010.

[78] K. Enjyoji, J. Sévigny, Y. Lin et al., "Targeted disruption of cd39/ATP diphosphohydrolase results in disordered hemostasis and thromboregulation," Nature Medicine, vol. 5, no. 9, pp. 1010-1017, 1999.

[79] C. Liu, S. Mather, Y. Huang, C. J. Garland, and X. Yao, "Extracellular ATP facilitates flow-induced vasodilatation in rat small mesenteric arteries," American Journal of Physiology-Heart and Circulatory Physiology, vol. 286, no. 5, pp. H1688-H1695, 2004.

[80] J. Pablo Huidobro-Toro and M. Veronica Donoso, "Sympathetic co-transmission: the coordinated action of ATP and noradrenaline and their modulation by neuropeptide $\mathrm{Y}$ in human vascular neuroeffector junctions," European Journal of Pharmacology, vol. 500, no. 1-3, pp. 27-35, 2004.

[81] A. M. Cardoso, F. H. Abdalla, M. D. Bagatini et al., "Swimming training prevents alterations in ecto-NTPDase and adenosine deaminase activities in lymphocytes from $\mathrm{N} \omega$-nitro-L-arginine methyl ester hydrochloride induced hypertension rats," Journal of Hypertension, vol. 33, no. 4, pp. 763-772, 2015.

[82] N. Mercier, T. O. Kiviniemi, A. Saraste et al., "Impaired ATP-induced coronary blood flow and diminished aortic NTPDase activity precede lesion formation in apolipoprotein E-deficient mice," The American Journal of Pathology, vol. 180, no. 1, pp. 419-428, 2012.

[83] A. Behdad, X. Sun, Z. Khalpey et al., "Vascular smooth muscle cell expression of ectonucleotidase CD39 (ENTPD1) is required for neointimal formation in mice," Purinergic Signalling, vol. 5, no. 3, pp. 335-342, 2009.

[84] F. Di Virgilio and A. Solini, "P2 receptors: new potential players in atherosclerosis," British Journal of Pharmacology, vol. 135, no. 4, pp. 831-842, 2002.

[85] A. B. Reiss and B. N. Cronstein, "Regulation of foam cells by adenosine," Arteriosclerosis, Thrombosis, and Vascular Biology, vol. 32, no. 4, pp. 879-886, 2012.

[86] A. Buchheiser, A. Ebner, S. Burghoff et al., "Inactivation of CD73 promotes atherogenesis in apolipoprotein Edeficient mice," Cardiovascular Research, vol. 92, no. 2, pp. 338-347, 2011.

[87] A. Zernecke, K. Bidzhekov, B. Ozuyaman et al., "CD73/ ecto- $5^{\prime}$-nucleotidase protects against vascular inflammation and neointima formation," Circulation, vol. 113, no. 17, pp. 2120-2127, 2006.

[88] J. Jalkanen, G. G. Yegutkin, M. Hollmen et al., “Aberrant circulating levels of purinergic signaling markers are associated with several key aspects of peripheral atherosclerosis and thrombosis," Circulation Research, vol. 116, no. 7, pp. 1206-1215, 2015.

[89] K. S. Vinapamula, S. V. Pemmaraju, S. K. Bhattaram, A. R. Bitla, and S. M. Manohar, "Serum adenosine deaminase as inflammatory marker in rheumatoid arthritis," Journal of Clinical and Diagnostic Research, vol. 9, no. 9, pp. BC08BC10, 2015.

[90] B. Kutryb-Zajac, P. Zukowska, M. Toczek et al., "Extracellular nucleotide catabolism in aortoiliac bifurcation of atherosclerotic ApoE/LDLr double knock out mice," Nucleosides, Nucleotides and Nucleic Acids, vol. 33, no. 4-6, pp. 323328, 2014

[91] H. Kalvegren, J. Fridfeldt, and T. Bengtsson, "The role of plasma adenosine deaminase in chemoattractant-stimulated oxygen radical production in neutrophils," European Journal of Cell Biology, vol. 89, no. 6, pp. 462-467, 2010. 
[92] R. Oguro, K. Kamide, T. Katsuya et al., "A single nucleotide polymorphism of the adenosine deaminase, RNAspecific gene is associated with the serum triglyceride level, abdominal circumference, and serum adiponectin concentration," Experimental Gerontology, vol. 47, no. 2, pp. 183-187, 2012.

[93] K. Stellos, A. Gatsiou, K. Stamatelopoulos et al., "Adenosine-to-inosine RNA editing controls cathepsin $\mathrm{S}$ expression in atherosclerosis by enabling HuR-mediated post-transcriptional regulation," Nature Medicine, vol. 22, no. 10, pp. 1140-1150, 2016.

[94] P. Kearney, M. Whelton, K. Reynolds, P. Muntner, P. Whelton, and J. He, "Global burden of hypertension: analysis of worldwide data," The Lancet, vol. 365, no. 9455, pp. 217-223, 2005.

[95] S. G. Mallat, B. Y. Tanios, H. S. Itani, T. Lotfi, and E. A. Akl, "Free versus fixed combination antihypertensive therapy for essential arterial hypertension: a systematic review and meta-analysis," PLoS One, vol. 11, no. 8, article e0161285, 2016.

[96] A. D. Lopez and C. D. Mathers, "Measuring the global burden of disease and epidemiological transitions: 2002-2030," Annals of Tropical Medicine \& Parasitology, vol. 100, no. 5-6, pp. 481-499, 2013.

[97] S. Fabbiano, M. Menacho-Márquez, J. Robles-Valero et al., "Immunosuppression-independent role of regulatory T cells against hypertension-driven renal dysfunctions," Molecular and Cellular Biology, vol. 35, no. 20, pp. 3528-3546, 2015.

[98] M. H. Helenius, S. Vattulainen, M. Orcholski et al., "Suppression of endothelial CD39/ENTPD1 is associated with pulmonary vascular remodeling in pulmonary arterial hypertension," American Journal of Physiology-Lung Cellular and Molecular Physiology, vol. 308, no. 10, pp. L1046L1057, 2015.

[99] S. H. Visovatti, M. C. Hyman, D. Bouis, R. Neubig, V. V. McLaughlin, and D. J. Pinsky, "Increased CD39 nucleotidase activity on microparticles from patients with idiopathic pulmonary arterial hypertension," PLoS One, vol. 7, no. 7, article e40829, 2012.

[100] J. L. McRae, P. A. Russell, J. S. Chia, and K. M. Dwyer, "Overexpression of CD39 protects in a mouse model of preeclampsia," Nephrology, vol. 18, no. 5, pp. 351355, 2013

[101] B. Rücker, M. E. Almeida, T. A. Libermann, L. F. Zerbini, M. R. Wink, and J. J. F. Sarkis, "E-NTPDases and ecto$5^{\prime}$-nucleotidase expression profile in rat heart left ventricle and the extracellular nucleotide hydrolysis by their nerve terminal endings," Life Sciences, vol. 82, no. 9-10, pp. 477-486, 2008.

[102] M. Ohta, K. Toyama, D. D. Gutterman et al., "Ecto$5^{\prime}$-nucleotidase, CD73, is an endothelium-derived hyperpolarizing factor synthase," Arteriosclerosis, Thrombosis, and Vascular Biology, vol. 33, no. 3, pp. 629-636, 2013.

[103] J. B. Sousa, M. S. Vieira-Rocha, C. Sa et al., "Lack of endogenous adenosine tonus on sympathetic neurotransmission in spontaneously hypertensive rat mesenteric artery," PLoS One, vol. 9, no. 8, article e105540, 2014.

[104] A. J. Akinyemi, G. R. Thome, V. M. Morsch et al., "Effect of ginger and turmeric rhizomes on inflammatory cytokines levels and enzyme activities of cholinergic and purinergic systems in hypertensive rats," Planta Medica, vol. 82, no. 7, pp. 612-620, 2016.
[105] A. J. Akinyemi, G. R. Thomé, V. M. Morsch et al., "Dietary supplementation of ginger and turmeric rhizomes modulates platelets ectonucleotidase and adenosine deaminase activities in normotensive and hypertensive rats," Phytotherapy Research, vol. 30, no. 7, pp. 1156-1163, 2016.

[106] A. M. Cardoso, M. D. Bagatini, C. C. Martins et al., "Exercise training prevents ecto-nucleotidases alterations in platelets of hypertensive rats," Molecular and Cellular Biochemistry, vol. 371, no. 1-2, pp. 147-156, 2012.

[107] C. C. Martins, M. D. Bagatini, A. M. Cardoso et al., "Regular exercise training reverses ectonucleotidase alterations and reduces hyperaggregation of platelets in metabolic syndrome patients," Clinica Chimica Acta, vol. 454, pp. 66-71, 2016.

[108] A. A. Nwankwo, E. E. Osim, and S. A. Bisong, "Contributory role of adenosine deaminase in metabolic syndrome," Nigerian Journal of Physiological Sciences, vol. 28, no. 1, pp. 73-76, 2013.

[109] R. Nemati, J. Lu, V. Ramachandran et al., "Association between the C34T polymorphism of the AMPD1 gene and essential hypertension in Malaysian patients," Genetics and Molecular Research, vol. 15, no. 2, 2016.

[110] S. P. Tofovic, H. Kusaka, P. Li, and E. K. Jackson, "Effects of adenosine deaminase inhibition on blood pressure in old spontaneously hypertensive rats," Clinical and Experimental Hypertension, vol. 20, no. 3, pp. 329-344, 1998.

[111] M. Franco, R. Bautista, O. Perez-Mendez et al., "Renal interstitial adenosine is increased in angiotensin II-induced hypertensive rats," American Journal of Physiology-Renal Physiology, vol. 294, no. 1, pp. F84-F92, 2008.

[112] O. O. Oladipo, B. B. Afolabi, and A. O. Okorodudu, "Adenosine deaminase activity in subjects with normal pregnancy, pregnancy induced hypertension and preeclampsia," West African Journal of Medicine, vol. 28, no. 3, pp. 161-164, 2009.

[113] C. A. M. Leal, D. B. R. Leal, S. A. Adefegha et al., "Platelet aggregation and serum adenosine deaminase (ADA) activity in pregnancy associated with diabetes, hypertension and HIV," Cell Biochemistry and Function, vol. 34, no. 5, pp. 343-350, 2016.

[114] T. Iriyama, K. Sun, N. F. Parchim et al., "Elevated placental adenosine signaling contributes to the pathogenesis of preeclampsia," Circulation, vol. 131, no. 8, pp. $730-$ 741,2015

[115] P. G. McDonald, M. O'Connell, and S. K. Lutgendorf, "Psychoneuroimmunology and cancer: a decade of discovery, paradigm shifts, and methodological innovations," Brain, Behavior, and Immunity, vol. 30, Supplement, pp. S1-S9, 2013.

[116] A. Mantovani, P. Allavena, A. Sica, and F. Balkwill, "Cancerrelated inflammation," Nature, vol. 454, no. 7203, pp. 436444, 2008.

[117] A. Manica, A. M. Da Silva, A. M. Cardoso et al., "High levels of extracellular ATP lead to chronic inflammatory response in melanoma patients," Journal of Cellular Biochemistry, vol. 119, no. 5, pp. 3980-3988, 2018.

[118] L. Antonioli, R. Colucci, C. Pellegrini et al., "The AMPK enzyme-complex: from the regulation of cellular energy homeostasis to a possible new molecular target in the management of chronic inflammatory disorders," Expert Opinion on Therapeutic Targets, vol. 20, no. 2, pp. 179191,2016 
[119] M. V. Sitkovsky, J. Kjaergaard, D. Lukashev, and A. Ohta, "Hypoxia-adenosinergic immunosuppression: tumor protection by T regulatory cells and cancerous tissue hypoxia," Clinical Cancer Research, vol. 14, no. 19, pp. 5947-5952, 2008.

[120] L. Antonioli, M. Fornai, R. Colucci et al., "Regulation of enteric functions by adenosine: pathophysiological and pharmacological implications," Pharmacology \& Therapeutics, vol. 120, no. 3, pp. 233-253, 2008.

[121] G. Hasko and P. Pacher, "Regulation of macrophage function by adenosine," Arteriosclerosis, Thrombosis, and Vascular Biology, vol. 32, no. 4, pp. 865-869, 2012.

[122] J. B. Sousa, P. Fresco, C. Diniz, and J. Goncalves, “Adenosine receptor ligands on cancer therapy: a review of patent literature," Recent Patents on Anti-Cancer Drug Discovery, vol. 13, no. 1, pp. 40-69, 2018.

[123] C. Cekic and J. Linden, "Purinergic regulation of the immune system," Nature Reviews Immunology, vol. 16, no. 3, pp. 177192, 2016.

[124] A. Young, D. Mittal, J. Stagg, and M. J. Smyth, "Targeting cancer-derived adenosine: new therapeutic approaches," Cancer Discovery, vol. 4, no. 8, pp. 879-888, 2014.

[125] R. S. Fisher, C. Acevedo, A. Arzimanoglou et al., "ILAE official report: a practical clinical definition of epilepsy," Epilepsia, vol. 55, no. 4, pp. 475-482, 2014.

[126] A. Vezzani, S. Balosso, and T. Ravizza, "Inflammation and epilepsy," Handbook of Clinical Neurology, vol. 107, pp. 163-175, 2012.

[127] R. Nicolaidis, A. N. Bruno, J. J. F. Sarkis, and D. O. Souza, "Increase of adenine nucleotide hydrolysis in rat hippocampal slices after seizures induced by quinolinic acid," Neurochemical Research, vol. 30, no. 3, pp. 385-390, 2005.

[128] F. Rassendren and E. Audinat, "Purinergic signaling in epilepsy," Journal of Neuroscience Research, vol. 94, no. 9, pp. 781-793, 2016.

[129] M. Alves, E. Beamer, and T. Engel, "The metabotropic purinergic P2Y receptor family as novel drug target in epilepsy," Frontiers in Pharmacology, vol. 9, p. 193, 2018.

[130] D. Boison, "Adenosinergic signaling in epilepsy," Neuropharmacology, vol. 104, pp. 131-139, 2016.

[131] I. Grundke-Iqbal, K. Iqbal, Y. C. Tung, M. Quinlan, H. M. Wisniewski, and L. I. Binder, "Abnormal phosphorylation of the microtubule-associated protein tau (tau) in Alzheimer cytoskeletal pathology," Proceedings of the National Academy of Sciences of the United States of America, vol. 83, no. 13, pp. 4913-4917, 1986.

[132] I. Ferrer, "Altered mitochondria, energy metabolism, voltagedependent anion channel, and lipid rafts converge to exhaust neurons in Alzheimer's disease," Journal of Bioenergetics and Biomembranes, vol. 41, no. 5, pp. 425-431, 2009.

[133] S. Hauptmann, I. Scherping, S. Drose et al., "Mitochondrial dysfunction: an early event in Alzheimer pathology accumulates with age in AD transgenic mice," Neurobiology of Aging, vol. 30, no. 10, pp. 1574-1586, 2009.

[134] L. D. Todorov, S. Mihaylova-Todorova, T. D. Westfall et al., "Neuronal release of soluble nucleotidases and their role in neurotransmitter inactivation," Nature, vol. 387, no. 6628, pp. 76-79, 1997.

[135] G. S. Pereira, T. Mello e Souza, A. M. O. Battastini, I. Izquierdo, J. J. F. Sarkis, and C. D. Bonan, "Effects of inhibitory avoidance training and/or isolated foot-shock on ectonucleotidase activities in synaptosomes of the anterior and posterior cingulate cortex and the medial precentral area of adult rats," Behavioural Brain Research, vol. 128, no. 2, pp. 121-127, 2002.

[136] C. D. Bonan, R. Roesler, G. S. Pereira, A. M. O. Battastini, I. Izquierdo, and J. J. F. Sarkis, "Learning-specific decrease in synaptosomal ATP diphosphohydrolase activity from hippocampus and entorhinal cortex of adult rats," Brain Research, vol. 854, no. 1-2, pp. 253-256, 2000.

[137] C. D. Bonan, M. M. Dias, A. M. O. Battastini, R. D. Dias, and J. J. F. Sarkis, "Inhibitory avoidance learning inhibits ectonucleotidases activities in hippocampal synaptosomes of adult rats," Neurochemical Research, vol. 23, no. 7, pp. 977-982, 1998.

[138] L. K. Parvathenani, S. Tertyshnikova, C. R. Greco, S. B. Roberts, B. Robertson, and R. Posmantur, " $\mathrm{P} 2 \mathrm{X}_{7}$ mediates superoxide production in primary microglia and is up-regulated in a transgenic mouse model of Alzheimer's disease," Journal of Biological Chemistry, vol. 278, no. 15, pp. 13309-13317, 2003.

[139] J. G. McLarnon, J. K. Ryu, D. G. Walker, and H. B. Choi, "Upregulated expression of purinergic $\mathrm{P} 2 \mathrm{X}_{7}$ receptor in Alzheimer disease and amyloid- $\beta$ peptide-treated microglia and in peptide-injected rat hippocampus," Journal of Neuropathology \& Experimental Neurology, vol. 65, no. 11, pp. 1090-1097, 2006.

[140] J. I. Diaz-Hernandez, R. Gomez-Villafuertes, M. León-Otegui et al., "In vivo P2X7 inhibition reduces amyloid plaques in Alzheimer's disease through GSK3 $\beta$ and secretases," Neurobiology of Aging, vol. 33, no. 8, pp. 1816-1828, 2012.

[141] D. Rampe, L. Wang, and G. E. Ringheim, "P2X7 receptor modulation of $\beta$-amyloid- and LPS-induced cytokine secretion from human macrophages and microglia," Journal of Neuroimmunology, vol. 147, no. 1-2, pp. 56-61, 2004.

[142] R. Kaddurah-Daouk, H. Zhu, S. Sharma et al., "Alterations in metabolic pathways and networks in Alzheimer's disease," Translational Psychiatry, vol. 3, no. 4, article e244, 2013.

[143] C. Isobe, T. Abe, and Y. Terayama, "Levels of reduced and oxidized coenzyme Q-10 and 8-hydroxy-2'-deoxyguanosine in the CSF of patients with Alzheimer's disease demonstrate that mitochondrial oxidative damage and/or oxidative DNA damage contributes to the neurodegenerative process," Journal of Neurology, vol. 257, no. 3, pp. 399-404, 2010.

[144] R. Kaddurah-Daouk, S. Rozen, W. Matson et al., "Metabolomic changes in autopsy-confirmed Alzheimer's disease," Alzheimer's \& Dementia, vol. 7, no. 3, pp. 309-317, 2011.

[145] M. Jove, M. Portero-Otin, A. Naudi, I. Ferrer, and R. Pamplona, "Metabolomics of human brain aging and age-related neurodegenerative diseases," Journal of Neuropathology \& Experimental Neurology, vol. 73, no. 7, pp. 640$657,2014$.

[146] H. Christensen, N. Maltby, A. F. Jorm, H. Creasey, and G. A. Broe, "Cholinergic 'blockade' as a model of the cognitive deficits in Alzheimer's disease," Brain, vol. 115, no. 6, pp. 1681-1699, 1992.

[147] M. D. KOPELMAN and T. H. CORN, "Cholinergic 'blockade' as a model for cholinergic depletion: a comparison of the memory deficits with those of Alzheimer-type dementia and the alcoholic Korsakoff syndrome," Brain, vol. 111, no. 5, pp. 1079-1110, 1988.

[148] K. A. Wesnes, P. M. Simpson, L. White et al., "Cholinesterase inhibition in the scopolamine model of dementia," Annals of the New York Academy of Sciences, vol. 640, no. 1, pp. 268271, 1991. 
[149] P. C. Marisco, F. B. Carvalho, M. M. Rosa et al., "Piracetam prevents scopolamine-induced memory impairment and decrease of NTPDase, $5^{\prime}$-nucleotidase and adenosine deaminase activities," Neurochemical Research, vol. 38, no. 8, pp. 1704-1714, 2013.

[150] J. M. Gutierres, F. B. Carvalho, M. R. C. Schetinger et al., "Protective effects of anthocyanins on the ectonucleotidase activity in the impairment of memory induced by scopolamine in adult rats," Life Sciences, vol. 91, no. 23-24, pp. 1221-1228, 2012.

[151] E. R. L. C. Vardy, K. A. B. Kellett, S. L. Cocklin, and N. M. Hooper, "Alkaline phosphatase is increased in both brain and plasma in Alzheimer's disease," Neurodegenerative Diseases, vol. 9, no. 1, pp. 31-37, 2012.

[152] M. Diaz-Hernandez, A. Gomez-Ramos, A. Rubio et al., "Tissue-nonspecific alkaline phosphatase promotes the neurotoxicity effect of extracellular tau," Journal of Biological Chemistry, vol. 285, no. 42, pp. 32539-32548, 2010.

[153] A. Gomez-Ramos, M. Diaz-Hernandez, R. Cuadros, F. Hernandez, and J. Avila, "Extracellular tau is toxic to neuronal cells," FEBS Letters, vol. 580, no. 20, pp. 48424850, 2006.

[154] K. A. Kellett, J. Williams, E. R. Vardy, A. D. Smith, and N. M. Hooper, "Plasma alkaline phosphatase is elevated in Alzheimer's disease and inversely correlates with cognitive function," International Journal of Molecular Epidemiology and Genetics, vol. 2, no. 2, pp. 114-121, 2011.

[155] J. A. Casal, A. Robles, and J. C. Tutor, "Serum markers of monocyte/macrophage activation in patients with Alzheimer's disease and other types of dementia," Clinical Biochemistry, vol. 36, no. 7, pp. 553-556, 2003.

[156] J. Jankovic, "Parkinson's disease: clinical features and diagnosis," Journal of Neurology, Neurosurgery \& Psychiatry, vol. 79, no. 4, pp. 368-376, 2008.

[157] L. S. Forno, "Neuropathology of Parkinson's disease," Journal of Neuropathology and Experimental Neurology, vol. 55, no. 3, pp. 259-272, 1996.

[158] T. Jiang, J. Hoekstra, X. Heng et al., "P2X7 receptor is critical in $\alpha$-synuclein-mediated microglial NADPH oxidase activation," Neurobiology of Aging, vol. 36, no. 7, pp. 23042318, 2015.

[159] M. Lee, N. Jantaratnotai, E. McGeer, J. G. McLarnon, and P. L. McGeer, " $\mathrm{Mg}^{2+}$ ions reduce microglial and THP-1 cell neurotoxicity by inhibiting $\mathrm{Ca}^{2+}$ entry through purinergic channels," Brain Research, vol. 1369, pp. 21-35, 2011.

[160] S. Uchida, T. Kadowaki-Horita, and T. Kanda, "Effects of the adenosine A2A receptor antagonist on cognitive dysfunction in Parkinson's disease," International Review of Neurobiology, vol. 119, pp. 169-189, 2014.

[161] T. Kadowaki Horita, M. Kobayashi, A. Mori, P. Jenner, and T. Kanda, "Effects of the adenosine $\mathrm{A}_{2 \mathrm{~A}}$ antagonist istradefylline on cognitive performance in rats with a 6-OHDA lesion in prefrontal cortex," Psychopharmacology, vol. 230, no. 3, pp. 345-352, 2013.

[162] S. Shiozaki, S. Ichikawa, J. Nakamura, S. Kitamura, K. Yamada, and Y. Kuwana, "Actions of adenosine A2A receptor antagonist KW-6002 on drug-induced catalepsy and hypokinesia caused by reserpine or MPTP," Psychopharmacology, vol. 147, no. 1, pp. 90-95, 1999.

[163] W. Hauber, P. Neuscheler, J. Nagel, and C. E. Muller, "Catalepsy induced by a blockade of dopamine $\mathrm{D}_{1}$ or $\mathrm{D}_{2}$ receptors was reversed by a concomitant blockade of adenosine $\mathrm{A}_{2 \mathrm{~A}}$ receptors in the caudate-putamen of rats," European Journal of Neuroscience, vol. 14, no. 8, pp. 1287-1293, 2001.

[164] P. Jenner, A. Mori, R. Hauser, M. Morelli, B. B. Fredholm, and J. F. Chen, "Adenosine, adenosine $\mathrm{A}_{2 \mathrm{~A}}$ antagonists, and Parkinson's disease," Parkinsonism \& Related Disorders, vol. 15, no. 6, pp. 406-413, 2009.

[165] M. Correa, A. Wisniecki, A. Betz et al., "The adenosine A2A antagonist KF17837 reverses the locomotor suppression and tremulous jaw movements induced by haloperidol in rats: possible relevance to parkinsonism," Behavioural Brain Research, vol. 148, no. 1-2, pp. 47-54, 2004.

[166] M. S. Medeiros, A. Schumacher-Schuh, A. M. Cardoso et al., "Iron and oxidative stress in Parkinson's disease: an observational study of injury biomarkers," PLoS One, vol. 11, no. 1, article e0146129, 2016.

[167] J. P. Oses, C. Batassini, D. Pochmann et al., "The hydrolysis of striatal adenine- and guanine-based purines in a 6-hydroxydopamine rat model of Parkinson's disease," Neurochemical Research, vol. 36, no. 2, pp. 215-222, 2011.

[168] N. Simola, M. Morelli, and A. R. Carta, "The 6hydroxydopamine model of Parkinson's disease," Neurotoxicity Research, vol. 11, no. 3-4, pp. 151-167, 2007.

[169] C. R. N. Polachini, R. M. Spanevello, E. A. Casali et al., "Alterations in the cholinesterase and adenosine deaminase activities and inflammation biomarker levels in patients with multiple sclerosis," Neuroscience, vol. 266, pp. 266-274, 2014.

[170] R. M. Spanevello, C. M. Mazzanti, R. Schmatz et al., "The activity and expression of NTPDase is altered in lymphocytes of multiple sclerosis patients," Clinica Chimica Acta, vol. 411, no. 3-4, pp. 210-214, 2010.

[171] R. M. Spanevello, C. M. Mazzanti, M. Bagatini et al., “Activities of the enzymes that hydrolyze adenine nucleotides in platelets from multiple sclerosis patients," Journal of Neurology, vol. 257, no. 1, pp. 24-30, 2010.

[172] R. M. Spanevello, C. M. Mazzanti, P. A. Maldonado et al., "Activities of enzymes that hydrolyze adenine nucleotides in platelets from rats experimentally demyelinated with ethidium bromide and treated with interferon- $\beta$," Life Sciences, vol. 80, no. 12, pp. 1109-1114, 2007.

[173] C. M. Mazzanti, R. M. Spanevello, A. Morsch et al., "Previous treatment with ebselen and vitamin $\mathrm{E}$ alters adenine nucleotide hydrolysis in platelets from adult rats experimentally demyelinated with ethidium bromide," Life Sciences, vol. 81, no. 3, pp. 241-248, 2007.

[174] R. Spanevello, C. M. Mazzanti, R. Schmatz et al., "Effect of vitamin $\mathrm{E}$ on ectonucleotidase activities in synaptosomes and platelets and parameters of oxidative stress in rats experimentally demyelinated," Brain Research Bulletin, vol. 80, no. 1-2, pp. 45-51, 2009.

[175] R. M. M. Spanevello, C. M. Mazzanti, R. Kaizer et al., “Apyrase and $5^{\prime}$-nucleotidase activities in synaptosomes from the cerebral cortex of rats experimentally demyelinated with ethidium bromide and treated with interferon- $\beta$," Neurochemical Research, vol. 31, no. 4, pp. 455-462, 2006.

[176] H. Lassmann, "Multiple sclerosis: lessons from molecular neuropathology," Experimental Neurology, vol. 262, Part A, pp. 2-7, 2014.

[177] S. Ljubisavljevic, "Oxidative stress and neurobiology of demyelination," Molecular Neurobiology, vol. 53, no. 1, pp. 744-758, 2016. 
[178] H. S. Domingues, C. C. Portugal, R. Socodato, and J. B. Relvas, "Oligodendrocyte, astrocyte, and microglia crosstalk in myelin development, damage, and repair," Frontiers in Cell and Development Biology, vol. 4, p. 71, 2016.

[179] M. M. Goldenberg, "Multiple sclerosis review," Pharmacy and Therapeutics, vol. 37, no. 3, pp. 175-184, 2012.

[180] E. F. Bondan, M. A. Lallo, H. Orsini et al., "Evaluation of locomotor activity after a local induction of toxic demyelination in the brainstem of Wistar rats," Arquivos de Neuro-Psiquiatria, vol. 64, no. 2b, pp. 496-503, 2006.

[181] J. Guimaraes and M. J. Sa, "Cognitive dysfunction in multiple sclerosis," Frontiers in Neurology, vol. 3, p. 74, 2012.

[182] M. Kipp, P. van der Valk, and S. Amor, "Pathology of multiple sclerosis," CNS \& Neurological Disorders - Drug Targets, vol. 11, no. 5, pp. 506-517, 2012.

[183] V. Siffrin, J. Vogt, H. Radbruch, R. Nitsch, and F. Zipp, "Multiple sclerosis - candidate mechanisms underlying CNS atrophy," Trends in Neurosciences, vol. 33, no. 4, pp. 202-210, 2010.

[184] A. R. Glabinski, M. Tani, V. K. Tuohy, and R. M. Ransohoff, "[13] Murine experimental autoimmune encephalomyelitis: a model of immune-mediated inflammation and multiple sclerosis," Methods in Enzymology, vol. 288, pp. 182-190, 1997.

[185] J. E. Merrill, "In vitro and in vivo pharmacological models to assess demyelination and remyelination," Neuropsychopharmacology, vol. 34, no. 1, pp. 55-73, 2009.

[186] O. M. Dumitrascu, K. R. Mott, and H. Ghiasi, "A comparative study of experimental mouse models of central nervous system demyelination," Gene Therapy, vol. 21, no. 6, pp. 599-608, 2014.

[187] R. Gold, H. P. Hartung, and K. V. Toyka, "Animal models for autoimmune demyelinating disorders of the nervous system," Molecular Medicine Today, vol. 6, no. 2, pp. 88-91, 2000.

[188] M. Cieslak, F. Kukulski, and M. Komoszynski, "Emerging role of extracellular nucleotides and adenosine in multiple sclerosis," Purinergic Signalling, vol. 7, no. 4, pp. 393402, 2011.

[189] G. Burnstock, U. Krugel, M. P. Abbracchio, and P. Illes, "Purinergic signalling: from normal behaviour to pathological brain function," Progress in Neurobiology, vol. 95, no. 2, pp. 229-274, 2011.

[190] O. Oyanguren-Desez, A. Rodriguez-Antiguedad, P. Villoslada, M. Domercq, E. Alberdi, and C. Matute, "Gain-of-function of P2X7 receptor gene variants in multiple sclerosis," Cell Calcium, vol. 50, no. 5, pp. 468-472, 2011.

[191] S. Amadio, S. Apolloni, N. D’Ambrosi, and C. Volonté, "Purinergic signalling at the plasma membrane: a multipurpose and multidirectional mode to deal with amyotrophic lateral sclerosis and multiple sclerosis," Journal of Neurochemistry, vol. 116, no. 5, pp. 796-805, 2011.

[192] C. Agresti, M. E. Meomartini, S. Amadio et al., “ATP regulates oligodendrocyte progenitor migration, proliferation, and differentiation: involvement of metabotropic P2 receptors," Brain Research Reviews, vol. 48, no. 2, pp. 157165, 2005.

[193] M. Fumagalli, D. Lecca, and M. P. Abbracchio, "CNS remyelination as a novel reparative approach to neurodegenerative diseases: the roles of purinergic signaling and the P2Y-like receptor GPR17," Neuropharmacology, vol. 104, pp. 8293, 2016.
[194] J. Ingwersen, B. Wingerath, J. Graf et al., "Dual roles of the adenosine A2a receptor in autoimmune neuroinflammation," Journal of Neuroinflammation, vol. 13, no. 1, p. 48, 2016.

[195] A. A. Fernandez-Ramos, V. Poindessous, C. MarchettiLaurent, N. Pallet, and M. A. Loriot, "The effect of immunosuppressive molecules on T-cell metabolic reprogramming," Biochimie, vol. 127, pp. 23-36, 2016.

[196] M. R. Bono, D. Fernandez, F. Flores-Santibanez, M. Rosemblatt, and D. Sauma, "CD73 and CD39 ectonucleotidases in $\mathrm{T}$ cell differentiation: beyond immunosuppression,” FEBS Letters, vol. 589, no. 22, pp. 3454-3460, 2015.

[197] Z. Saze, P. J. Schuler, C. S. Hong, D. Cheng, E. K. Jackson, and T. L. Whiteside, "Adenosine production by human B cells and B cell-mediated suppression of activated T cells," Blood, vol. 122, no. 1, pp. 9-18, 2013.

[198] T. L. Whiteside and E. K. Jackson, "Adenosine and prostaglandin $\mathrm{E}_{2}$ production by human inducible regulatory $\mathrm{T}$ cells in health and disease," Frontiers in Immunology, vol. 4, p. 212, 2013.

[199] E. Safarzadeh, F. Jadidi-Niaragh, M. Motallebnezhad, and M. Yousefi, "The role of adenosine and adenosine receptors in the immunopathogenesis of multiple sclerosis," Inflammation Research, vol. 65, no. 7, pp. 511-520, 2016.

[200] M. Cieslak and M. Komoszynski, "The role of ecto-purines in inflammation leading to demyelination - new means for therapies against multiple sclerosis," Neurologia $i$ Neurochirurgia Polska, vol. 45, no. 5, pp. 489-499, 2011.

[201] S. Amadio, C. Montilli, R. Magliozzi, G. Bernardi, R. Reynolds, and C. Volonte, "P2Y12 receptor protein in cortical gray matter lesions in multiple sclerosis," Cerebral Cortex, vol. 20, no. 6, pp. 1263-1273, 2010.

[202] W. Beaino, B. Janssen, G. Kooij et al., "Purinergic receptors P2Y12R and P2X7R: potential targets for PET imaging of microglia phenotypes in multiple sclerosis," Journal of Neuroinflammation, vol. 14, no. 1, p. 259, 2017.

[203] L. Chen and C. F. Brosnan, "Exacerbation of experimental autoimmune encephalomyelitis in $\mathrm{P}_{2} \mathrm{X}_{7} \mathrm{R}^{-1-}$ mice: evidence for loss of apoptotic activity in lymphocytes," The Journal of Immunology, vol. 176, no. 5, pp. 3115-3126, 2006.

[204] G. Q. Chen, Y. Y. Chen, X. S. Wang et al., "Chronic caffeine treatment attenuates experimental autoimmune encephalomyelitis induced by guinea pig spinal cord homogenates in Wistar rats," Brain Research, vol. 1309, pp. 116-125, 2010.

[205] T. Grygorowicz, M. Wełniak-Kamińska, and L. Strużyńska, "Early P2X7R-related astrogliosis in autoimmune encephalomyelitis," Molecular and Cellular Neurosciences, vol. 74, pp. 1-9, 2016.

[206] T. Grygorowicz, L. Struzynska, G. Sulkowski, M. Chalimoniuk, and D. Sulejczak, "Temporal expression of P2X7 purinergic receptor during the course of experimental autoimmune encephalomyelitis," Neurochemistry International, vol. 57, no. 7, pp. 823-829, 2010.

[207] B. J. Gu, J. Field, S. Dutertre et al., "A rare P2X7 variant Arg307Gln with absent pore formation function protects against neuroinflammation in multiple sclerosis," Human Molecular Genetics, vol. 24, no. 19, pp. 5644-5654, 2015.

[208] Y. Liu, H. Zou, P. Zhao et al., "Activation of the adenosine A2A receptor attenuates experimental autoimmune encephalomyelitis and is associated with increased intracellular calcium levels," Neuroscience, vol. 330, pp. 150-161, 2016. 
[209] C. Matute, I. Torre, F. Perez-Cerda et al., "P2X 7 receptor blockade prevents ATP excitotoxicity in oligodendrocytes and ameliorates experimental autoimmune encephalomyelitis," Journal of Neuroscience, vol. 27, no. 35, pp. 95259533, 2007.

[210] G. Mameli, V. Astone, G. Arru et al., "Brains and peripheral blood mononuclear cells of multiple sclerosis (MS) patients hyperexpress MS-associated retrovirus/HERV-W endogenous retrovirus, but not human herpesvirus 6," Journal of General Virology, vol. 88, no. 1, pp. 264274, 2007.

[211] M. Mecha, A. Feliu, P. M. Inigo, L. Mestre, F. J. CarrilloSalinas, and C. Guaza, "Cannabidiol provides long-lasting protection against the deleterious effects of inflammation in a viral model of multiple sclerosis: a role for A2A receptors," Neurobiology of Disease, vol. 59, pp. 141-150, 2013.

[212] A. Mildner, H. Huang, J. Radke, W. Stenzel, and J. Priller, " $\mathrm{P} 2 \mathrm{Y}_{12}$ receptor is expressed on human microglia under physiological conditions throughout development and is sensitive to neuroinflammatory diseases," Glia, vol. 65, no. 2, pp. 375-387, 2017.

[213] A. D. Sadovnick, B. J. Gu, A. L. Traboulsee et al., "Purinergic receptors P2RX4 and P2RX7 in familial multiple sclerosis," Human Mutation, vol. 38, no. 6, pp. 736-744, 2017.

[214] A. J. Sharp, P. E. Polak, V. Simonini et al., "P2x7 deficiency suppresses development of experimental autoimmune encephalomyelitis," Journal of Neuroinflammation, vol. 5, no. 1, p. 33, 2008.

[215] S. Tsutsui, J. Schnermann, F. Noorbakhsh et al., "A1 adenosine receptor upregulation and activation attenuates neuroinflammation and demyelination in a model of multiple sclerosis," Journal of Neuroscience, vol. 24, no. 6, pp. 1521-1529, 2004.

[216] Y. Yiangou, P. Facer, P. Durrenberger et al., "COX-2, CB2 and P2X7-immunoreactivities are increased in activated microglial cells/macrophages of multiple sclerosis and amyotrophic lateral sclerosis spinal cord," BMC Neurology, vol. 6, no. 1, p. 12, 2006.

[217] I. Lavrnja, I. Bjelobaba, M. Stojiljkovic et al., "Time-course changes in ectonucleotidase activities during experimental autoimmune encephalomyelitis," Neurochemistry International, vol. 55, no. 4, pp. 193-198, 2009.

[218] J. M. Fletcher, R. Lonergan, L. Costelloe et al., "CD39 ${ }^{+}$Foxp $3^{+}$ regulatory $\mathrm{T}$ cells suppress pathogenic Th17 cells and are impaired in multiple sclerosis," Journal of Immunology, vol. 183, no. 11, pp. 7602-7610, 2009.

[219] G. Borsellino, M. Kleinewietfeld, D. Di Mitri et al., "Expression of ectonucleotidase CD39 by Foxp3 ${ }^{+}$Treg cells: hydrolysis of extracellular ATP and immune suppression," Blood, vol. 110, no. 4, pp. 1225-1232, 2007.

[220] Y. Baqi, "Ecto-nucleotidase inhibitors: recent developments in drug discovery," Mini-Reviews in Medicinal Chemistry, vol. 15, no. 1, pp. 21-33, 2015.

[221] C. D. Bonan, "Ectonucleotidases and nucleotide/nucleoside transporters as pharmacological targets for neurological disorders," CNS \& Neurological Disorders - Drug Targets, vol. 11, no. 6, pp. 739-750, 2012.

[222] M. al-Rashida and J. Iqbal, "Therapeutic potentials of ecto-nucleoside triphosphate diphosphohydrolase, ectonucleotide pyrophosphatase/phosphodiesterase, ecto- $5^{\prime}$ nucleotidase, and alkaline phosphatase inhibitors," Medicinal Research Reviews, vol. 34, no. 4, pp. 703-743, 2014. 


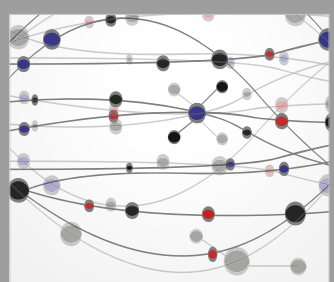

The Scientific World Journal
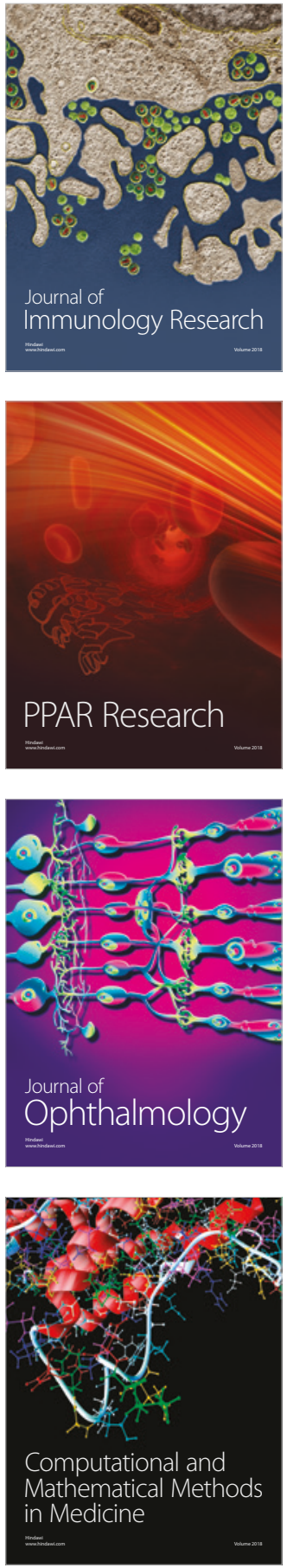

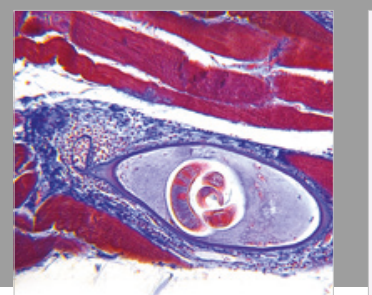

Gastroenterology Research and Practice

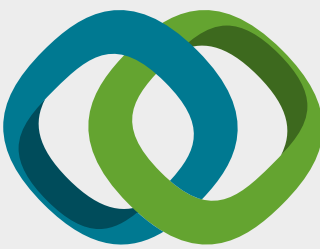

\section{Hindawi}

Submit your manuscripts at

www.hindawi.com
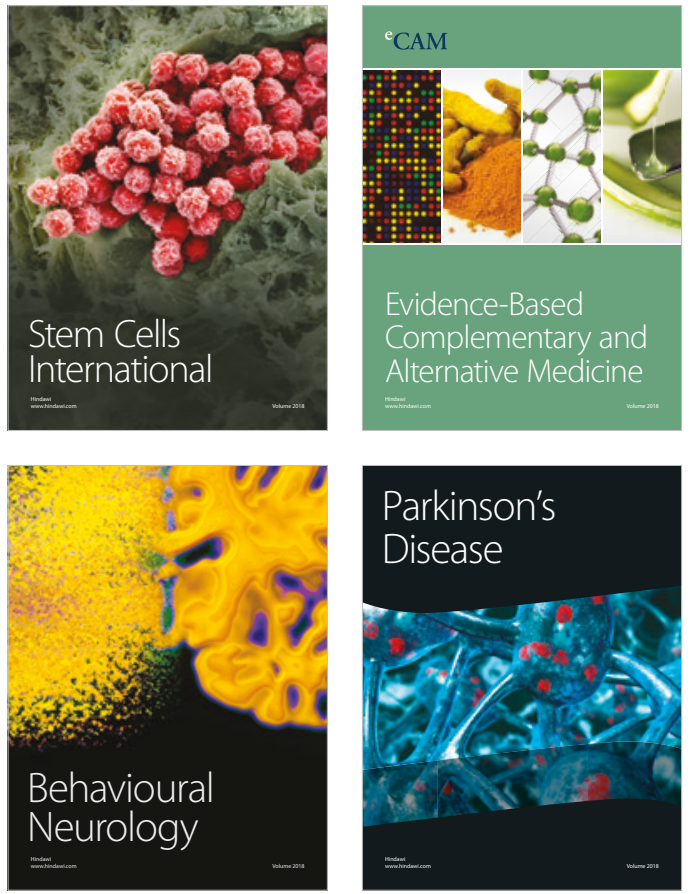

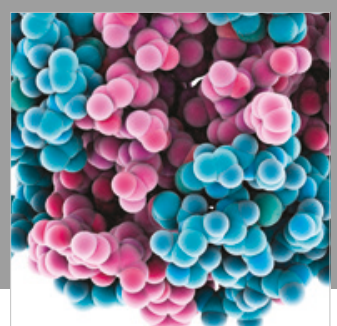

ournal of

Diabetes Research

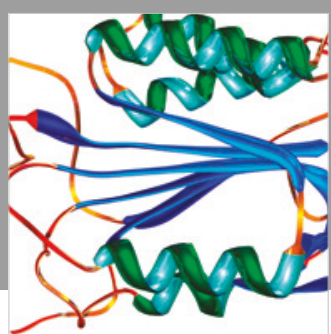

Disease Markers
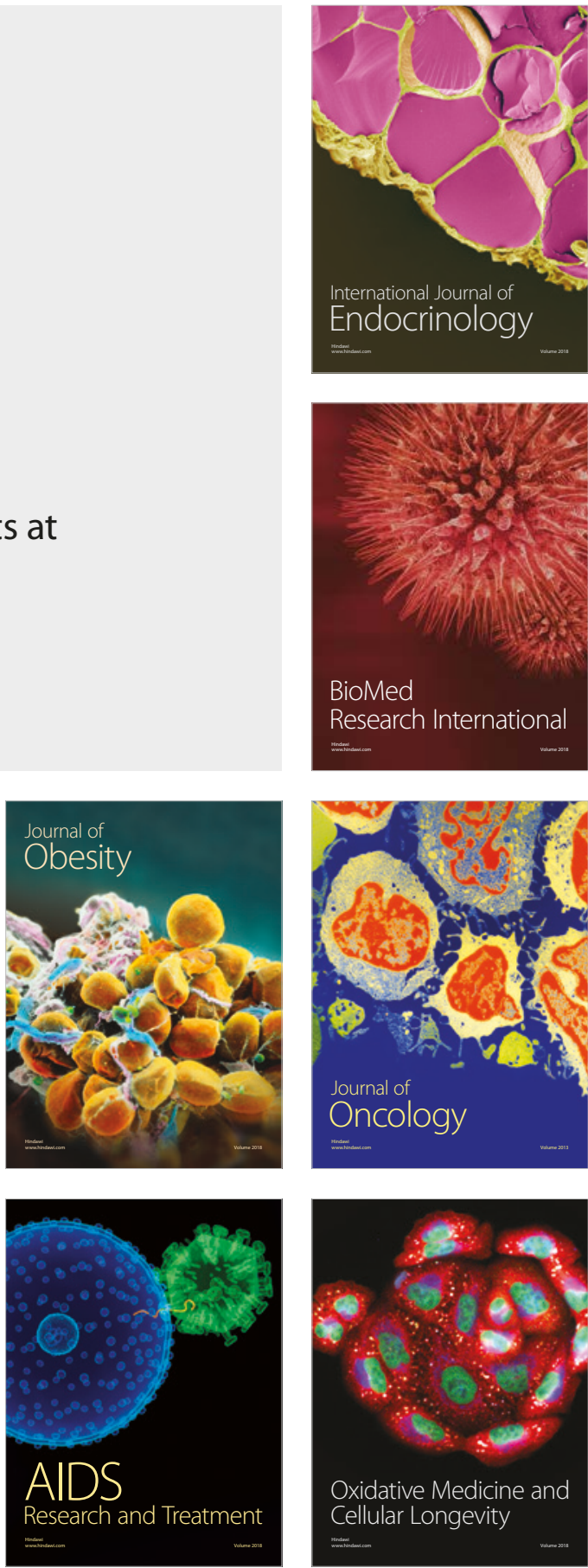